\title{
ALDAMA-ENEA 1913-2013. UN EJEMPLO DE ARQUITECTURA NEORRENACENTISTA EN SAN SEBASTIÁN
}

\section{NAIARA ARDANAZ IÑARGA}

Universidad de Navarra

Resumen: En 1913 se construyó Aldama-Enea, villa de recreo de los marqueses de Aldama en DonostiaSan Sebastián y obra del prestigioso arquitecto madrileño José María Mendoza Ussía. El edificio guarda una gran unidad en todos sus elementos decorativos, entre los que destacan los azulejos Ruiz de Luna y las vidrieras de la Casa Maumejean. Más adelante también intervino en algunas reformas el arquitecto donostiarra Eduardo Lagarde. La gran finca incluía otros edificios entre los que se encuentra Etxe Zuri, antigua sede provisional de las Juntas Generales de Guipuzkoa.

Palabras clave: José María Mendoza Ussía, marqués de Aldama, Ruiz de Luna, Casa Maumejean, arquitectura neorrenacentista, azulejería, vidriera.

Abstract: Aldama-Enea, the recreational villa of the Marquis de Aldama, was built in 1913 in St.Sebastian, designed by the prestigious architect José María Mendoza Ussía. The building holds a large unit in all of its decorative elements, among them the tiles made by Ruiz de Luna and the stained glasses from Maumejean House. Later some reforms were made by the architect Eduardo Lagarde, from St.Sebastian. The large estate included among other buildings Etxe Zuri, former provisional headquarters of the Juntas Generales de Guipuzcoa.
Keywords: José María Mendoza Ussía, Marquis de Aldama, Ruiz de Luna, Maumejean House, neo-renaissance architecture, tiling industry, stined glass.

Résumé: Aldama Enea (1913) une villa de plaisance, domaine privé du marquis d'Aldama à Saint Sébastien. C'est un bâtiment prestigieux de I'architecte Jose Maria Mendoza Ussía. Le bâtiment garde une grande unité dans tous ses éléments décoratifs parmi lesquels figurent les carreaux de faïence de Ruiz de Luna et les vitraux de la Maison Maumejean. Plus tard I'architecte Eduardo Lagarde de San Sebastien fera quelques réformes. La grande propiété contenait d'autres bâtiments parmi lesquels on trouve la maison Etxe Zuri ancien siège provisoire des "Juntas Generales"de Guipuzcoa.

Mots-clés: José María Mendoza Ussía, Marquis de Aldama, Ruiz de Luna, Maison Maumejean, neorenaissance, carreaux de faïence, vitrage.
Aldama-Enea1913-2013.Anexample of Neo-Renaissance architecture in San Sebastián

Aldama-Enea1913-2013. Unexemple de l'architecture néo-Renaissance à San Sebastián. 
Aldama-Enea, Eva-Enea o Villa Eva son denominaciones de un edificio que nos muestran además de un cambio de propietario parte de la vida y de la historia de la ciudad de San Sebastián. Desde 1913 este "hotel" o villa forma parte de la vista del monte Ayete desde cualquier punto de la bahía de la Concha. Este edificio, que en su origen fue parte de una de las mayores fincas que había en el municipio, ha tenido mejor suerte que otros muchos construidos en la misma época o un poco antes debido a las distintas reformas urbanas y expansión llevadas a cabo en la ciudad. Su relevancia también se debe a que en sus distintas etapas ha sido sede de encuentro de personalidades destacadas de la nobleza, la política, la diplomacia, la empresa y la sociedad (Fig. 1).

El análisis del edificio no ha sido sencillo pues apenas se ha conservado documentación de los anteriores propietarios teniendo que recurrir en algunos casos a la prensa de la época. En primer lugar se ha realizado una breve semblanza de los propietarios y su contextualización en el entorno temporal y geográfico, en segundo lugar nos aproximaremos a la trayectoria de su arquitecto, José María Mendoza Ussía, para poder valorar el edificio y en tercer lugar analizaremos Aldama Enea e indicaremos las principales modificaciones que se han realizado hasta el momento actual ${ }^{1}$.

\section{Una residencia de verano para los marqueses de Aldama}

San Sebastián, a lo largo del XIX, se fue definiendo como ciudad estacional de vacaciones y reposo de la familia real y, como consecuencia, comenzó a

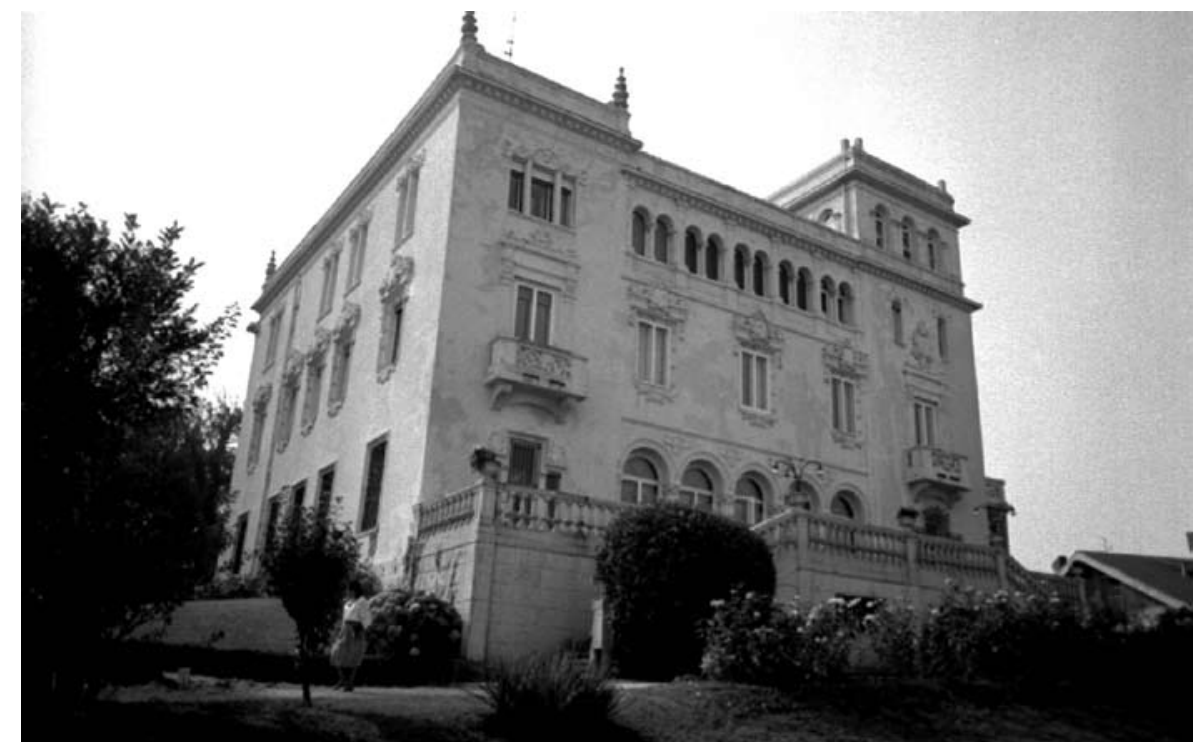

Fig. 1) Donostia-San Sebastiain. Aldama-Enea. Fachada principal. Fotografía: Luis Fernández Conde. Archivo Multimedia, Uniersidad de Navarra.

atraer a un turismo dispuesto a disfrutar, además de la belleza del entorno, de todo lo que podían ofrecer ciudades balnearios como Baden Baden, Brighton, Ostende o Biarritz, con sus baños de mar, hoteles, casinos, salas de fiestas, teatros, cines, cafés, carreras de caballos y automóviles, etc.

El momento decisivo en que la ciudad se consagra como ciudad moderna y cosmopolita será durante la Primera Guerra Mundial. Además de las

1. Agradezco la información que me han podido facilitar a Eva Astondoa Arocena, hija de los segundos propietarios y a José María Castillejo, conde de Floridablanca y marqués de Aldama, nieto del primer propietario. También agradezco las indicaciones de las consultas realizadas al Dr. Jaume Coll Conesa, Director del Museo Nacional de Cerámica, al Dr. Alfonso Pleguezuelo de la Universidad de Sevilla, a

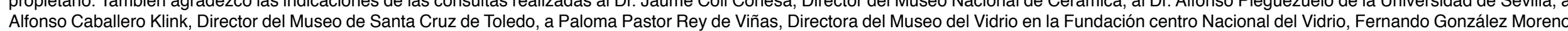

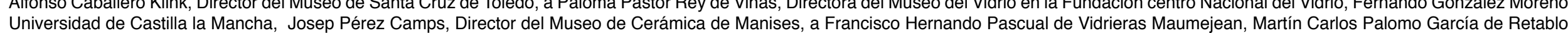

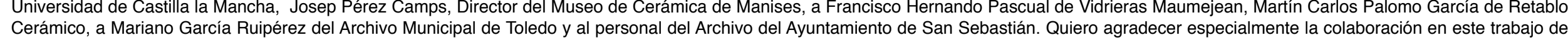
investigación al Prof. Daniel Bartolomé, por su interés y entusiasmo. 
diversiones mencionadas, San Sebastián sería considerada una de la ciudades europeas más moderas por la electricidad, el tranvía, el teléfono automático, los funiculares, el higienismo y la sanidad².

La ciudad fue creciendo a través de los ensanches y viviendas de pisos caracterizándose por el eclecticismo propio del momento, mientras que a lo largo de la vertiente septentrional se construyeron viviendas unifamiliares destacando el palacio real de Miramar.

Es precisamente una de esas residencias unifamiliares a la que vamos a dedicar este artículo, Aldama-Enea, propiedad de Francisco Ussía y Cubas, marqués de Aldama.

El propietario había nacido el 10 de diciembre de 1880 en Madrid y fue el primer hijo de Luis Ussía y Aldama, II marqués de Aldama, y María de Cubas Erice. Fue el sucesor en el marquesado tras la muerte de su padre en 1908.

Luis Ussía Aldama era natural de Llodio y contrajo matrimonio con la hija de los primeros marqueses de Fontalba en 1861. En 1893 recibió el título de marqués de Aldama, creado por Alfonso XIII el 4 de febrero de ese año, y se le concedió la Grandeza de España el 27 de julio de 1922.
En 1883 el marqués y su cuñado, Juan Manuel de Urquijo, constituyeron la Sociedad Urquijo y Compañía con medio millón de pesetas de capital. Esta colaboración duró hasta 1904 momento en el que el ya marqués de Aldama dejó a su socio y decidió abrir Aldama y Compañía en la calle Alcalá ${ }^{3}$.

Los marqueses residían en el centro de la capital madrileña pero también poseían una finca en la Moraleja que solían frecuentar. Tuvieron cinco hijos, Francisco, José Luis, futuro conde de los Gaitanes, Consuelo, Ramón y Jesús. Los dos mayores estudiaron derecho y trabajaron en el negocio familiar, la sociedad Aldama y Compañía dedicada a la Banca en la calle Alcalá 4 .

Sus primos, los Urquijo, prefirieron la seguridad de los negocios a diferencia de los hermanos Ussía y Cubas, destacados emprendedores de la aristocracia madrileña, que se aventuraron en nuevos caminos en el mundo financiero como la industria del cine, la de telefonía o la eléctrica. Junto con Oriol Urquijo estuvieron presentes en los consejos de administración de las más importantes empresas eléctricas del país ${ }^{5}$.

Francisco Ussía formó parte del grupo Banesto, del consejo de administración del Banco Vitoria y participó activamente en la creación del Banco Central; de hecho, hubo un periodo en el que esta entidad se confundía con Aldama y Compañía. El Banco Central sustituyó a la casa Aldama y para su constitución

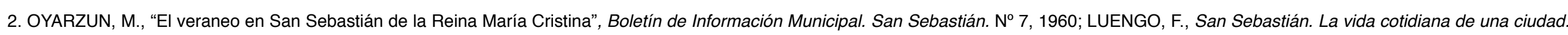
De su destrucción a la Ciudad Contemporánea. (Sus gentes, costumbres, imagen, sociabilidad), Txertoa, San Sebastián, 1984 . p. 100 y ss.

3. Díaz Hernández, O., Los marqueses de Urquijo: el apogeo de una saga poderosa y los inicios del Banco Urquijo, 1870-1931, Universidad de Navarra, Ediciones Universidad de Navarra. EUNSA, 1998, pp. 152-159; "El Banco Urquijo: un banco industrial fundado en el periodo de entreguerras", Revista de la historia de la economía y de la empresa, №. 1, 2007 (Ejemplar dedicado a: Instituciones

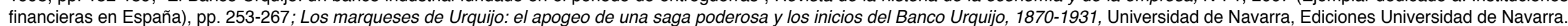
EUNSA, 1998, p. 51 .

EUNSA, 1998, p. 51.
4. Revista llustrada de Banca, "Banco Urquijo", 1925.

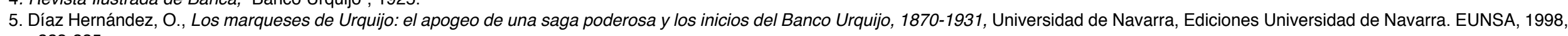
pp. 223-225. 
aglutinó en 1919 distintas instituciones financieras como Crédito Unión Minera, Hijos de Rodríguez Acosta, Crédito Navarro, Banco Guipuzcoano, Banco de Santander, Banco Castellano y Banco de Crédito de Zaragoza y los accionistas Jiménez Arenas y López Jiménez ${ }^{6}$.

Francisco Ussía, al igual que otros miembros de la "Casa", denominación acuñada por los contemporáneos para referirse a los miembros familia Urquijo y Ussía, participó en política siendo diputado por el distrito de Torrelaguna, senador del reino por la provincia de Madrid, desde 1918 hasta 1920, y miembro del Congreso de los Diputados de España por el distrito de Getafe desde el 8 de mayo de 1923 hasta el 15 de septiembre de $1923^{7}$.

En 1925 tuvo lugar la suspensión de pagos del Crédito de Unión Minera y el Banco Central. Las pérdidas fueron de 2,3 millones de pesetas y también afectaron a otras compañías como la Compañía Española de Minas del Rif o el Banco de Vitoria que era filial del Banco Español de Crédito.

Los dos hermanos Ussía fueron encarcelados y posteriormente exonerados mediante acuerdos extrajudiciales entre la liquidadora del banco y los denunciados a cambio de importantes sumas de dinero, que principalmente aportó la madre de éstos hipotecando varias fincas urbanas ${ }^{8}$. Fue el año de la quiebra, 1925, el momento en el que los marqueses se debieron ver obligados a desprenderse del hotel de San Sebastián como otros bienes.

Desde el punto de vista social los matrimonios de la saga sirvieron para emparentar a sus miembros con personas del mismo status, permitiendo una mayor vinculación a la élite social y económica. Onésimo Hernández también apunta que se produjo una unión mayor entre la aristocracia vasca y madrileña dando lugar a la fusión de los Urquijo, Gandarias y Ussía con los Cubas, Federico y Losada.

La presencia de los marqueses y su participación en la vida social de San Sebastián se puede conocer a través de la prensa de la época. Tenemos noticia de su participación en la inauguración de la central telefónica de la ciudad en 1913, también en las carreras de caballos en el hipódromo de Lasarte que contaba con la presencia de la familia real. Precisamente en 1923 ganó las carreras su caballo, Pontón ${ }^{9}$ También asistió a la feria de fotografía de esta ciudad al ser miembro del Consejo de administración de la Sociedad Industrial Fotográfica Española el año $1922^{10}$.

El 12 de enero de 1925 la finca denominada antes "Aldama-enea", que en lo futuro sería "Eva-enea", compuesta de un hotel o casa principal, cuadras, cocheras y garajes, pabellón de portería, caserío, fortín, paseos y jardines, señalada con el número tres del barrio de Lugariz, fue vendida a Don

6. AUBANELL JUBANY, A. M., "Estrategia empresarial y estrategia financiera de la Sociedad Hidroeléctrica Española, 1907-1935”, Revista de Historia Industrial, $\mathrm{n}^{\circ} 17,2000, \mathrm{pp} .153-185$. Blanco y Negro 20/05/1923. Los bancos de Barcelona. El Banco Central de Barcelona.

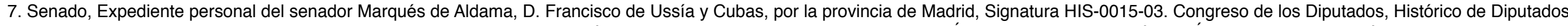

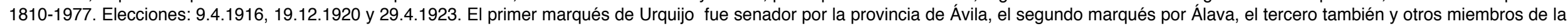

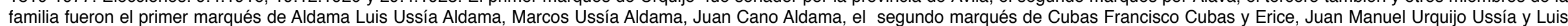

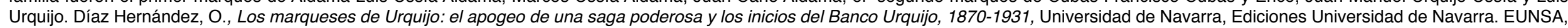
1998, p. 108

8. ALONSO OLEA, E. J., "El Crédito de la Unión Minera: 1901-2002", Historia contemporánea, ISSN 1130-2402, № 24, 2002 (Ejemplar dedicado a: Historia Urbana), pp. 323-354.

9. ABC, 21/08/1913, p. 13; Blanco y Negro 09/09/1923, p. 7.

10. ABC 16/09/1922, p. 6. Dentro del consejo de administración, entre otros, se encontraban también sus familiares José María Mendoza Ussía, el conde de los Gaitanes. 
Francisco Arocena Gurruchaga y Doña Evangelina Astondoa Amat, vecinos de Tolosa pero residentes en $\mathrm{Cuba}^{11}$.

Toda la familia Arocena-Astondoa volvió a trasladarse a Cuba de modo permanente en 1937, residiendo en la Habana hasta 1945. Durante aquel periodo, y para que la vivienda no se deteriorase, alquilaron la casa a Teotonio Pereira embajador de Portugal en España ${ }^{12}$. Tras el conflicto bélico el embajador fue destinado a Brasil $(1945-1947)^{13}$ y la familia Arocena regresó a San Sebastián.

A partir de mayo de 1960 se llevó a cabo la nacionalización de las compañías azucareras en Cuba, uno de los negocios al que se dedicaba la familia. Francisco Arocena tuvo que desprenderse de la finca Eva-Enea y se parceló siendo adquirida por particulares, la Diputación y la Universidad de Navarra.

\section{José María Mendoza Ussía en el contexto de la arquitectura madrileña del momento}

José María Mendoza (Madrid 1886-1943) formó parte de una generación de arquitectos que en el primer cuarto del siglo XX dejaron huella en el patrimonio histórico y cultural de Madrid.

Siguiendo la tradición profesional de la familia José María Mendoza Ussía se tituló en la Escuela de Arquitectura de Madrid en 1906. Los años de formación y de ejercicio coinciden con el de los acalorados debates sobre la arquitectura que debía predominar en la capital y en el país, que se hicieron eco tanto en el ámbito académico como en la prensa. Algunos defendían la necesidad de recibir y participar de las tendencias vigentes en el exterior, como los historicismos, el modernismo o el eclecticismo, otros reclamaban estilos autóctonos. A la vez que coexistían estas tendencias también se dieron dentro de la obra de un mismo arquitecto.

La Exposición Universal de París de 1900 con el pabellón realizado por José de Urioste en estilo neoplateresco fue el punto de partida de los regionalismos. Lamperez, al tratar sobre la arquitectura moderna y el eclecticismo, criticaba la constante imitación de modelos extranjeros. En concreto al hablar de la arquitectura privada en Madrid hacía énfasis en el escaso progreso frente a edificios de carácter público. Las tres tendencias imperantes dentro del eclecticismo eran el "neo-griego", la "moderna escuela ojival" y los "estilos nacionales, plateresco y mudéjar"14.

En este contexto se desarrollará la carrera de nuestro arquitecto, quien participó en el desarrollo constructivo de la Gran Vía trabajando en equipo con José de Aragón y Pradera.

José María Mendoza Ussía era pariente de la familia Urquijo, primo del marqués de Cubas y Fontalba y del marqués de Aldama, con los que mantuvo

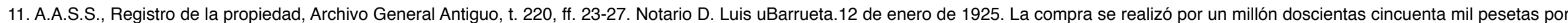
la finca propiamente dicha y veinte y cinco mil pesetas por los muebles.

12. Entrevista a Eva Arocena Astondoa. 1 de marzo de 2012-03-02.

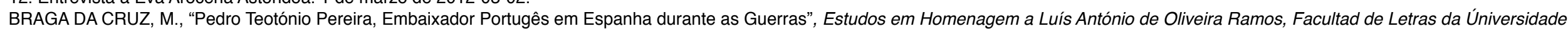
do Porto, 2004

13. Otros destinos fueron Washington (1947-1950), Londres (1953-1958) y posteriormente ocupó cargos en el gobierno de Portugal falleciendo en 1972 en Lisboa.

14. ROCHA ARANDA, O. da, El modernismo en la arquitectura madrileña. Génesis y desarrollo de una opción ecléctica, CSIC, Madrid, 2009, p. 92. 
una estrecha relación y fue responsable de la realización de diferentes edificios y viviendas de los mismos. Precisamente su etapa más fructífera y de proyectos más ambiciosos fue principalmente la segunda década del siglo al diseñar notables edificios para sus familiares: el Banco Urquijo en Gran Vía, n4 (1917-1919), viviendas y oficinas para el Marqués de Urquijo en Gran Vía n6 (1917-1919,) y el Palacio del Marqués de Fontalba y Cubas en el Paseo de la Castellana $n^{\circ} 17$. También cabe destacar otros ejemplos como el Edificio Meneses en la Plaza Canalejas (1915), un cine con Ignacio de Aldama y Elorz Rialto en Gran Vía n 54 (1930), y el cine Azul en el nº 76 de la misma calle (1933) y el edificio de la Papelera Española en la Calle Mejía Lequerica $n^{\circ} 8$ (1913).

Mendoza Ussía con el paso de los años fue depurando la ornamentación de las fachadas de sus edificios que podemos encontrar con bastante profusión en obras como el palacio del marqués de Fontalba, la Papelera Española en Madrid y en Aldama Enea.

El arquitecto no fue una excepción a la hora de procurar una integración total de las artes decorativas con el entorno arquitectónico. La presencia de cerámicas, rejería, vidrieras, escayolas se repite en varias de sus obras sometiéndose al estilo deseado.

Precisamente en el Madrid del momento florecían las artes industriales que se adaptaron al eclecticismo y al modernismo vigentes. Entre ellos cabe citar a vidrieros como Lázaro Lampérez y los Hermanos Maumejean o ceramistas como Zuloaga o Ruiz de Luna ${ }^{15}$. Precisamente encontraremos a Mendoza Ussía encargando obras a la casa Maumejean y Ruiz de Luna en sus proyectos.
Antes de entrar a analizar el edificio en cuestión tenemos que ponerlo en relación con otro trabajo, ya mencionado, de Mendoza Ussía, una de sus obras más destacadas, el palacio del marqués de Cubas y Fontalba (Fig.2). Es posible que las trazas de los dos edificios se realizasen en un mismo espacio de tiempo pues la construcción del segundo también tuvo lugar en 1912. Como reconocimiento a la calidad del edificio el premio a la mejor construcción realizada en Madrid el año 1914 fue para la "casa-palacio" del marqués de Cubas y Fontalba proyectada por este arquitecto y su socio José Aragón y Pradera ${ }^{16}$. Fue un premio en el que pesó la habilidad sobre la decoración y las modernas instalaciones interiores en las que la limpieza se realizaba "eléctricamente" y ser el primer edificio privado en el que una centralita telefónica comunicaba las principales dependencias. El premio, además del reconocimiento, consistió en la entrega de una cantidad de cinco mil pesetas.

El edificio está rodeado por jardines y verja, a semejanza de otras viviendas burguesas del paseo de la Castellana o del barrio de Salamanca, elementos que realzan la monumentalidad de la fachada. Ésta está dividida en tres cuerpos remados por una balaustrada entre pedestales y un gran escudo en el eje central.

El palacio es de planta rectangular de 985 metros de superficie y tres plantas, además de semisótano. Todas las estancias (antedespacho, despacho, gran salón, billar, capilla, etc.) se organizan en torno a un gran hall cubierto en la planta principal y están conectadas con ese espacio central. Éste es el espacio más suntuoso y más artístico del edificio, lugar en el cual tenían lugar los principales encuentros sociales.

15. ROCHA ARANDA, O. da, El modernismo en la arquitectura madrileña. Génesis y desarrollo de una opción ecléctica, CSIC, Madrid, 2009, p. 173.

16. El palacio, situado en el paso de la Castellana $n^{\circ} 17$, fue sede del Tribunal de Justicia Militar a partir de 1944 y posteriormente de la Fiscalía del Estado, desde 1991. 


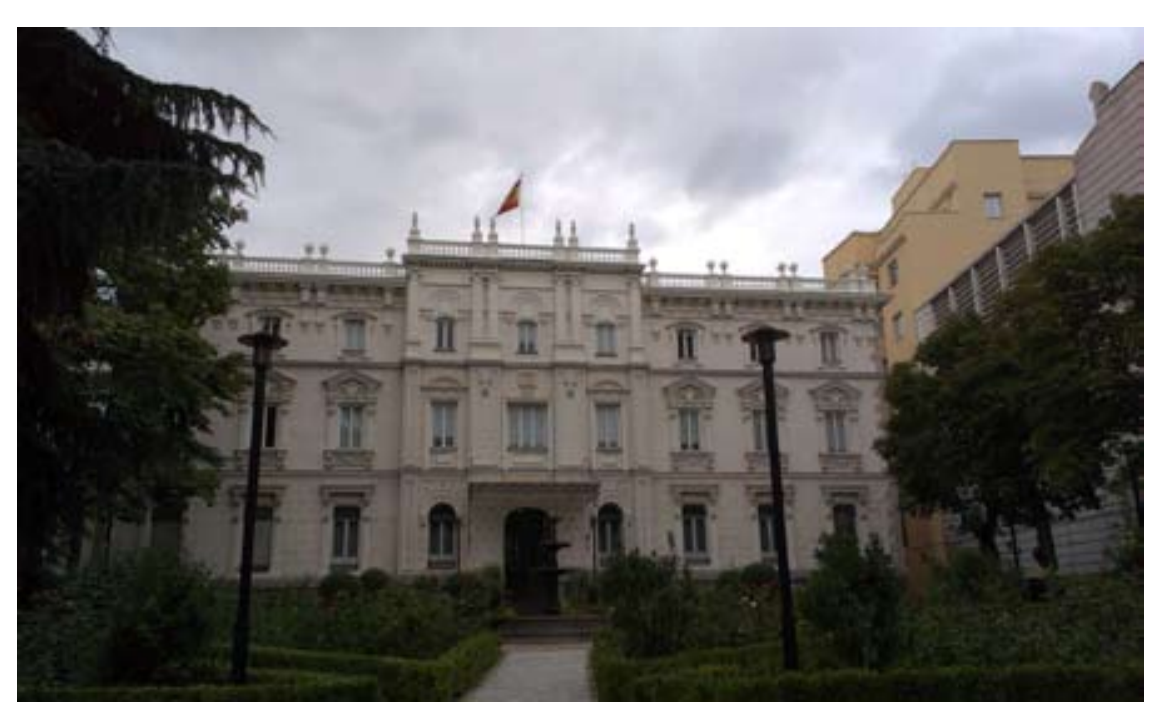

Fig. 2) Madrid. Palacio de marqués de Fontalba-Fiscalía General del Estado. Fachada principal

En la planta inferior o semisótano se encontraban las estancias de trabajo del servicio: cocina, bodega, despensa y depósito de carbón.

Los espacios privados, los destinados a dormitorios de los propietarios y huéspedes, los baños y tocadores, se encontraban en el primer piso. Por último, en la planta superior, bajo la cubierta, se hallaban los dormitorios de los criados.

En él, tanto en el interior -en el gran patio central- como al exterior encontramos profusión de elementos decorativos. Algunos elementos se repetirán en los proyectos posteriores aunque su estilo evolucionaría hacia una disminución de ornamentación en las fachadas.

Salvando las diferencias de ambos edificios, una vivienda familiar frente a otra destinada al periodo vacacional, existen semejanzas en la primacía de la decoración sobre la originalidad arquitectónica, la coherencia de dicha decoración en todos los espacios, la distribución de las estancias en torno a dos patios centrales cubiertos con grandes lucernarios y en los diferentes niveles, el uso de un eje de distribución entre el acceso y la escalera principal, así como la incorporación de todas las comodidades de la época y avances tecnológicos.

\section{El edificio}

Aldama-Enea fue concebida como una residencia de verano u "hotel". Esta denominación, que se puso de moda con la restauración Alfonsina, deja de manifiesto la impronta francesa tanto en la designación como en el concepto. Nada tenían que ver con los antiguos y grandes palacios aristocráticos y la nueva aristocracia y la alta burguesía financiera que erigirá esta tipología de edificios tanto en sus lugares de residencia como de veraneo. Estas viviendas eran edificios aislados y exentos, modernos y confortables ${ }^{17}$.

Aldama-Enea, pensada como espacio de recreo para disfrutar del periodo estival en San Sebastián, nos recuerda a una villa renacentista orientada a los jardines. Pero también, a semejanza de otros modelos de arquitectura ecléctica, encontraremos espacios decorados con estilos exóticos.

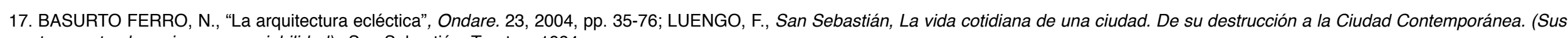
gentes, costumbres, imagen, sociabilidad), San Sebastián. Txertoa. 1984. 
Encontramos sin lugar a dudas ecos del célebre pabellón de José de Urioste en la Exposición Universal de París de 1900, realizado en estilo neoplateresco y que tomaban como modelos al Palacio Monterrey y la Universidad de Alcalá de Henares.

En esas fechas, en Madrid, el mismo arquitecto del pabellón diseñó la casa -actualmente museo- de Lázaro Galdiano, diseñada en $1903^{18}$, con características semejantes al citado pabellón, y cuyo diseño fue reformado por los arquitectos Joaquín Kramer y Francisco Borrás. Pero su influencia también se hizo notar en otras ciudades como el ayuntamiento de Valladolid o el Teatro Victoria Eugenia de San Sebastián erigido por el arquitecto Francisco de Urcola, finalizándose su construcción en 1912.

El emplazamiento original, situado actualmente en la Cuesta de Aldapeta número 49 , se encontraba en una zona escasamente urbanizada de San Sebastián en el momento de su construcción. El lugar era denominado Pintorenea, nombre que correspondía al caserío que existía en el mismo. Limitaba la finca con el camino que llevaba a Hernani y por el norte con la propiedad del marqués de Valmediano.

Don Francisco Ussía y Cubas, adquirió el terreno por doscientas veinte y siete mil quinientas pesetas el 21 de octubre de $1912^{19}$. Ese mismo año se presentó el proyecto de construcción de un nuevo edificio y otros anejos en los terrenos de Pintorenea como cuadras, cochera y garajes y pabellón de portería ${ }^{20}$
La descripción del nuevo edificio en el documento notarial fue la siguiente: "Un hotel o casa principal construido de mampostería sus traviesas verticales y con vigas de hierro de doble T las horizontales y con bovedilla de resilla: consta de sótanos y tres pisos: en los sótanos se hallan las cocinas y dependencias de esta; en el piso bajo están situados el hall y habitaciones de recibo, comedor, salón, todo ello decorado con adornos de escayola, damascos, frisos de madera y azulejos de Talavera; en el piso principal existen los dormitorios pintados al esmalte y los cuartos de baño uniendo a ambos pisos una escalera de mármol, en el piso segundo se hallan los dormitorios de criados, lavadero y cuarto de plancha, sus paramentos están pintados al temple, a la altura de este piso esta vidriera artística que cubre el hall en la parte posterior de este piso existe una terraza; tiene este edificio una torre en la que existe una habitación; todos los pisos están unidos entre si por una escalera interior de piedra artificial; los herrajes del piso bajo son de bronce, el resto son corrientes; los vidrios son belgas de una pieza; la carpintería es moldada a dos haces, la cubierta es de madera con teja plana, la fachada es de mampostería y piedra artificial revocados a la catalana: mide este edificio cuatrocientos ochenta y tres metros y sesenta y tres decímetros cuadrados y estima su valor en ciento ochenta mil pesetas" ${ }^{21}$.

La descripción del nuevo edificio en el documento notarial fue la siguiente: "Un hotel o casa principal construido de mampostería sus traviesas verticales y con vigas de hierro de doble $T$ las horizontales y con bovedilla de resilla: consta de sótanos y tres pisos: en los sótanos se hallan las cocinas y dependencias de esta; en el piso bajo están situados el hall y habitaciones

18. Fue miembro de la delegación española capitaneada por José Urioste en la Exposición Universal de París en 1900. El éxito de esta delegación hizo que el neoplateresco fuese el estilo predominante

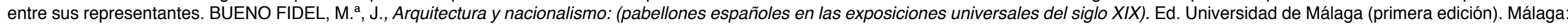
Colegio de Arquitectos, 1979, pp. 93-102.

19. 3-Compra.

20. Además seguía existiendo un fortín y el antiguo caserío. El primero se modificó y el segundo fue destruido.

21. 4 Edificación- Doc notarial 4 de octubre de 1913. 
de recibo, comedor, salón, todo ello decorado con adornos de escayola, damascos, frisos de madera y azulejos de Talavera; en el piso principal existen los dormitorios pintados al esmalte y los cuartos de baño uniendo a ambos pisos una escalera de mármol, en el piso segundo se hallan los dormitorios de criados, lavadero y cuarto de plancha, sus paramentos están pintados al temple, a la altura de este piso esta vidriera artística que cubre el hall en la parte posterior de este piso existe una terraza; tiene este edificio una torre en la que existe una habitación; todos los pisos están unidos entre si por una escalera interior de piedra artificial; los herrajes del piso bajo son de bronce, el resto son corrientes; los vidrios son belgas de una pieza; la carpintería es moldada a dos haces, la cubierta es de madera con teja plana, la fachada es de mampostería y piedra artificial revocados a la catalana: mide este edificio cuatrocientos ochenta y tres metros y sesenta y tres decímetros cuadrados y estima su valor en ciento ochenta mil pesetas"22.

La ausencia de documentación dificulta notablemente entender cómo ha ido modificándose el edificio desde su construcción. Un análisis de los planos originales nos permite ver algunos cambios llevados a cabo durante la construcción del mismo. Entre los planos conservados en el Archivo municipal -pues echamos en falta dos plantas- encontramos la fachada, el alzado y la primera planta y la tercera (Fig. 3).

La fachada norte, o principal, recuerda a los modelos mencionados del arquitecto José de Urioste, aunque al dar a un jardín en la planta inferior se añade una galería con vanos de medio punto, a modo de logia cerrada que, a su vez, da a una terraza con balaustre y una escalera que desciende a través de dos rampas también abalaustradas al espacio ajardinado. Destacan en el último piso la galería de arquillos y columnillas que se repiten también en el torreón. Rematan la fachada una serie de pináculos que decoran la terraza superior y torreón.

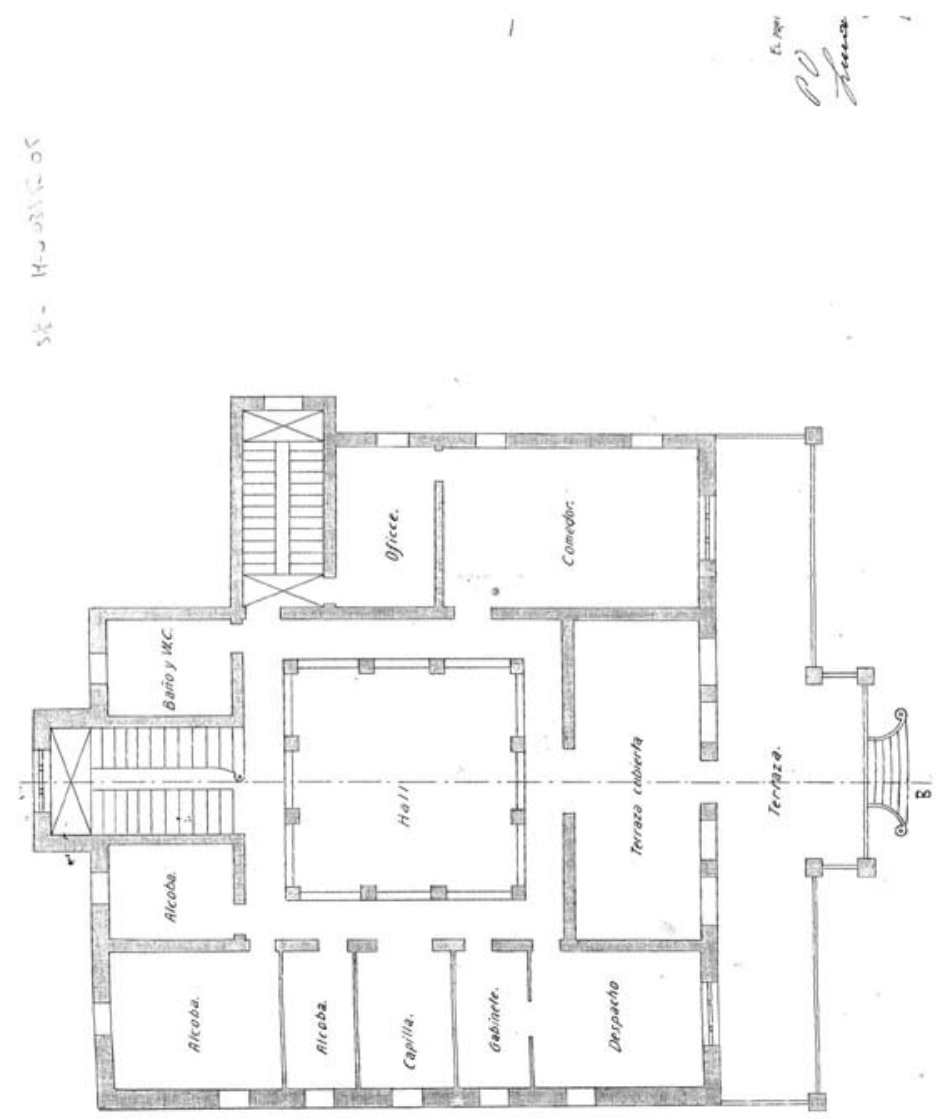

Fig. 3) Donostia-San Sebastián. Aldama-Enea. Primera planta (1916). Archivo del Ayuntamiento de Donostia-San Sebastián 
El estado actual no corresponde totalmente con el del plano el Ayuntamiento. Se puede observar que se llegaron a suprimir algunos de los vanos o no se resaltó el extremo izquierdo a modo de torreón rebajado. Destaca también modificación de la escalera del jardín, en lugar de ser una única y que descendiese hacia el frente se desdobló en dos tramos perpendiculares ya desde el principio por los planos del 1916 donde se vuelve a dibujar la estructura original pero no tenemos certeza de esto.

En el exterior, a partir del año 1963, en algún momento en el que se habrían llevado a cabo obras de saneamiento de la fachada o cubierta, se suprimieron una serie de pináculos que decoraban el torreón que tampoco correspondían con los del diseño inicial. Esto se ha podido comprobar gracias a las imágenes extraídas de la película rodada en 1963 en este edificio, El diablo en vacaciones de José Elorrieta ${ }^{23}$, y algunas fotografías de los primeros años de ISSA $^{24}$. También se suprimieron unas lámparas de hierro forjado que salían de dos los jarrones de la terraza a modo de flores.

De la fachada surúnicamente cabe mencionar la antigua puerta de acceso que hasta hace poco cerraban unas grandes rejas. Posteriormente volveremos a mencionar este acceso pero muy posiblemente, al construir el edificio, debió modificarse la función de la estancia a la que da y se debió abrir como acceso principal al edificio. La actual puerta principal de orientación norte, salvo los meses de verano, resulta ciertamente incómoda por lo que su traslado a la fachada sur convendría tanto para resguardarse de las inclemencias del tiempo como para permitir la aproximación de los vehículos.
En el interior de este edificio de planta cuadrada encontramos un amplio hall dividido en dos niveles, a modo de patio, al que se accede por la fachada norte y sur (Fig. 4). Todas las estancias de este espacio con carácter de representación y recepción se organizan en torno al mismo: salitas, despacho, capilla, comedor. Pasamos de una planta cuadrada a una octogonal mediante una serie de ocho columnas corintias dispuestas por parejas que tiene su continuidad en el segundo piso y que da al hall a través de una balconada. La ligera apariencia de octógono se enfatiza con la cubierta adaptada a este segundo espacio. El hall se cierra en la parte superior por una amplia vidriera cenital de temática mitológica. En ambas plantas hay, además, dos zócalos de cerámica destacables que trataremos más adelante. Hasta los años 70 las paredes estuvieron forradas con papel de seda roja confiriendo a la estancia un carácter absolutamente distinto por el fuerte contraste con el azul predominante de los zócalos, frente al blanco que actualmente cubre paredes y elementos arquitectónicos de todo el hall.

La decoración historicista está inspirada en motivos platerescos y se extiende a todos los elementos que conforman el espacio: vidrieras, azulejos, ebanistería, muebles y trabajos de escayola que se extiende por los frisos, capiteles, jambas y zócalos: sirenas aladas, cabezas de angelotes, cartelas, bustos, yelmos, bucráneos, calaveras, trofeos y putti.

Prácticamente todas las puertas del hall están enmarcadas en madera a modo de arco rebajado con un importante trabajo de ebanistería y algunas figuras en relieve. La fuente de inspiración es posible que estuviese en la catedral de Toledo, precisamente en la capilla de Santiago, como puede observarse en una edición antigua de unos tondos renacentistas con 


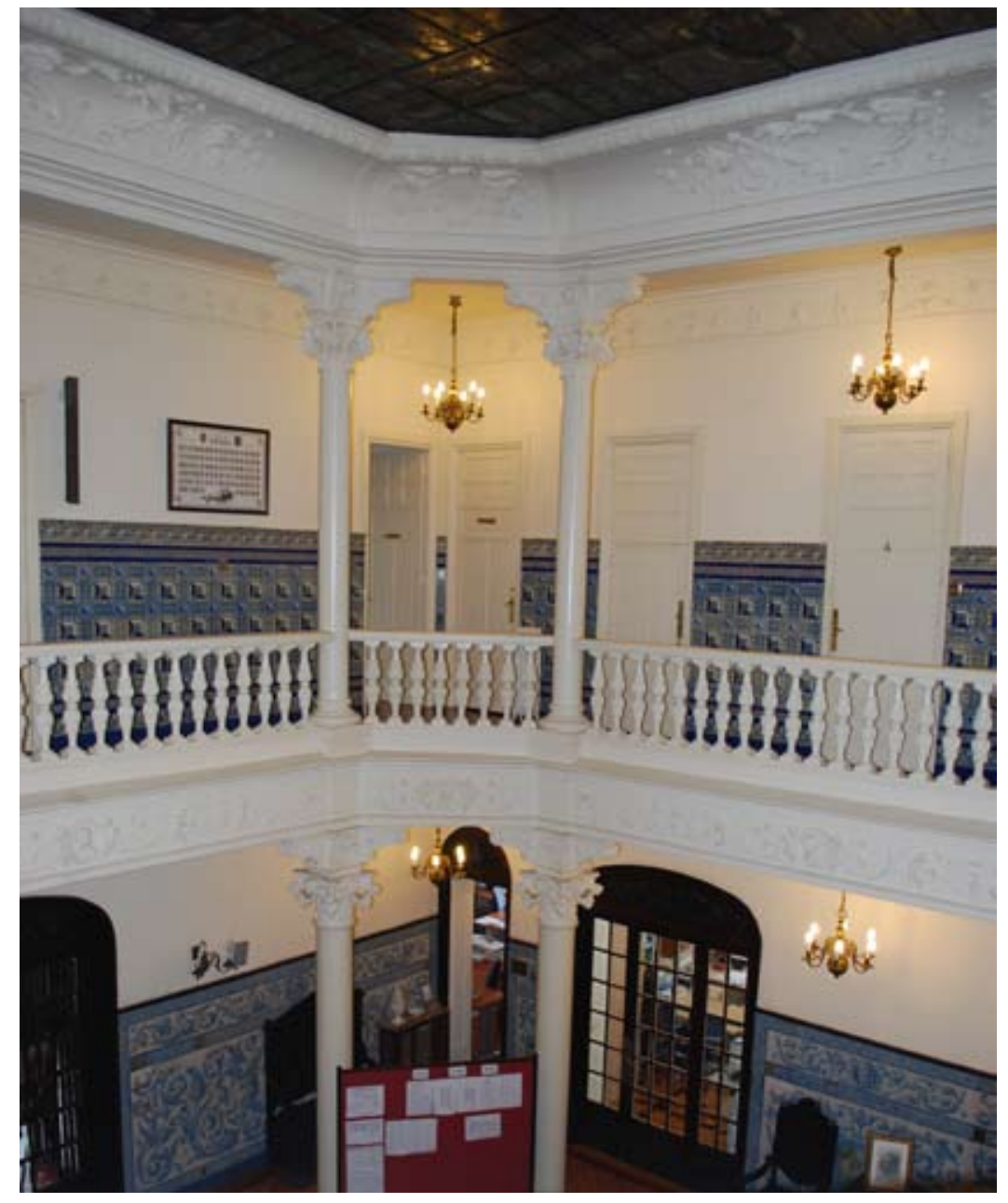

Fig. 4) Donostia-San Sebastián. Aldama-Enea. Interior cabezas de soldados que sobresalen ${ }^{25}$. Estos motivos se repiten, formando un conjunto, en el zócalo de cerámica como trataremos más adelante. En la parte inferior de las puertas también encontramos mascarones femeninos con motivos vegetales.

Al entrar en el hall, en eje con el acceso al edificio, destaca la escalera con una barandilla abalaustrada y escalones de mármol de dos tramos. A la altura del descansillo se dispone un gran vano con vidriera que ilumina todo el espacio de la escalera rematada por dos putti que sostienen un escudo inscrito en una corona de laurel con una llama en la parte superior y roleos vegetales flanqueándolos.

Las estancias de la planta baja que dan al hall prácticamente se conservan en su estado original aunque en la actualidad tienen otras funciones.

Contrastando con el plano de dicha planta se observa que algunos espacios debieron ser modificados en el momento de su construcción. El zócalo de los azulejos y las puertas de acceso a las estancias debieron de disponerse de este modo desde el inicio pues no se observa ninguna fragmentación o modificación. En el plano constan despacho, gabinete, tres alcobas, baño y W.C., Oficce, comedor y terraza cubierta. La realidad fue que la capilla ocupó dos alcobas anejas. La alcoba siguiente debió modificarse también desde el inicio, como se ha mencionado, para servir de acceso al edificio.

Nos detendremos en alguna de las estancias de esta planta ya que, prácticamente el resto de espacios originales del edificio han desaparecido. El primero de los espacios al que accedemos en la actualidad es el denominado en el plano como terraza cubierta, un espacio cubierto que se asemeja a una

25. LORDA, J., Classical Architecture, The Grand Manner, http://www.unav.es/ha/indice.html. (Consultado el 17-6-2014). 
serre, a modo de invernadero que solían dar al jardín y realizaban funciones de sala de estar. Esa estancia es el actual recibidor de entrada, denominada por los segundos propietarios patio o sala andaluza, por la decoración con un zócalo de azulejería de Triana y la existencia de una fuente en el centro, actualmente desaparecida. Se contempla el jardín y la bahía a través de una serie de arcos rematados por vidrieras. A ambos extremos de la sala hay dos grandes vanos, protegidos por una celosía de hierro forjado. Dichas rejerías se decoran con planchas caladas de motivos vegetales de hojas y florones estilizados y están rematadas en la parte superior con roleos. Cierra la puerta de acceso al hall una gran reja de dos hojas de hierro forjado a modo de cancela abalaustrada.

En la sala destaca, como ya se ha mencionado, el zócalo de cerámica de vivos colores que la rodea prácticamente en su totalidad. No tenemos datos de su procedencia pero por las características estilísticas debe proceder de Sevilla y posiblemente de la fábrica de José Mensaque y Vera. Acompaña a la decoración de la estancia la solería decorada conolambrillas, losetas pequeñas de diseño tradicional andaluz, que se suelen colocar en el suelo como adorno intercaladas entre losas de barro para formar diferentes combinaciones.

En 1963 la capilla pasó de su lugar original al espacio del comedor conservándosela puerta de acceso, una reja dorada con un relieve policromado en el que se representa el bautismo de Cristo, también en dicho espacio.

La alcoba situada entre la capilla -hoy es una salita- y la escalera, fue la puerta de acceso hasta época reciente. La decoración de inspiración renacentista se extiende por toda la estancia. La pared que da al exterior consta de un gran arco rebajado cerrado por una gran reja ornamentada y cristal. A los lados se disponen dos pilastras corintias con decoración que se asemeja a candelieri y que se remata con el friso que corre por toda la estancia decorada con fuentes de frutas y roleos vegetales.

Como elementos decorativos que encontramos entre los barrotes de ambos paños de la reja hay dos cartelas que penden con dos óvalos dorados en el centro. En la parte superior entre los roleos se encuentran dos letras en mayúscula superpuestas, inscritas en un óvalo que se repiten tanto en el interior como en el exterior. Son las iniciales de los apellidos de los segundos dueños de la casa, Arocena y Astondoa.

La cubierta, también de inspiración renacentista, es plana y está decorada con casetones decorados con ovas y motivos vegetales policromados en oro.

También tenemos que mencionar el aseo, en el mismo lugar que consta en el plano, pero posiblemente modificado en 1931. La instalación de cuarto de baño no es un asunto trivial ya que constituyó una auténtica revolución en la vida doméstica. Hasta finales del siglo XIX no hay un espacio específico para la higiene dentro de las viviendas. La aparición de estas estancias se da cuando el agua corriente llega a los hogares. Es a partir de 1900 cuando se empieza a ver en los planos una habitación al lado de los dormitorios principales que se señala como WC y baño.

El presente cuarto de baño se encuentra ricamente decorado con láminas de ónice verde y naranja. Dos cúpulas rebajadas decoradas con relieves de flores de un aspecto metalizado cubren la estancia. Nos consta la intervención del arquitecto Eduardo Lagarde ${ }^{26}$ en otro edificio de la propiedad en esa fecha y muy posiblemente también en este en los dos cuartos de baño por la presencia de dos vidrieras Art decó en la casa.

En la actualidad no existe la bañera y el lavabo fue desplazado con la supresión de la misma. 
Continuando con las estancias que dan al hall finalmente se encuentra la puerta de acceso a lo que originalmente fue el comedor de la casa y en la actualidad es un oratorio. La estancia está dividida en dos espacios. El primero y más amplio tiene una planta cuadrangular con un gran vano y las antiguas puertas de servicio del Office a la par. El segundo espacio, en un nivel superior, tiene dos grandes columnas corintias para diferenciarlo del primero. El capitel y la basa están policromados en dorado y el fuste imita al mármol en tonos azules. El otro extremo tiene las equinas achaflanadas dando lugar a un espacio poligonal y, a los dos lados, dos vanos. Apenas ha cambiado la estructura y se conservan las molduras de madera de las paredes. Únicamente hay que mencionar que el papel de seda adamascado de color amarillo fue sustituido por otro muy semejante en verde, como se puede comprobar en la filmación mencionada.

En la planta inferior del edificio, correspondiente a los sótanos, se encontraban las cocinas y otras dependencias del servicio a las que se accedían por la escalera de servicio que también daba al hall, al oficce y a la primera y segunda planta.

La segunda planta, también abierta al hall, repite la estructura de columnas y frisos de la primera. Sobre el entablamento arranca la bóveda que se incurva cerrándose con un lucernario decorado con una gran vidriera artística.

Esta planta únicamente conserva la estructura de acceso a las antiguas estancias destinadas a espacios privados. Desde finales del siglo XIX se generalizaen lascasadeclasemedialapresencia delosdormitoriosprincipales, los de los hijos, separados por sexos, y en ocasiones los de las criadas.

En este caso se conserva el espacio correspondiente al dormitorio principal con algún adorno de escayola original, que daba a una habitación aneja, posiblemente con función de tocador.

Nuevamente el hecho de respetar el zócalo de azulejos ha facilitado la conservación de los marcos de las puertas, algunas con escaso sentido en la actualidad, y que dan cierta idea de la distribución de las distintas estancias. Sabemos de la existencia de otro aseo muy ricamente decorado y de una habitación china de la que se conservan algunos muebles en otros espacios. Ésta se situaba encima de la capilla. La habitación estaba forrada con papel chinesco y mobiliario decorado con figuras chinescas y paisajes que aún permanecen en el edificio aunque en otro emplazamiento.

La tercera planta desde su origen fue un espacio destinado a habitaciones de servicio o invitados y todas las estancias han sido modificadas sin conservar nada destacable.

En el plano del alzado del edificio de 1912 se observa la ausencia de parte de ese nivel que da hacia el sur y vemos que se añadieron en 1916, al elevar parte del piso. Cuatro cuartos, tal como se indica, que se añaden a otros siete espacios cuya función desconocemos (Fig. 5). Desde este piso se accede, por una escalera de caracol, al torreón y tejado-terraza del edificio.

26. Apenas tenemos más noticias sobre otras posibles intervenciones de este polifacético arquitecto pero queremos incluir algunos datos biográficos debido a su destacada y reconocida carrera: "Militar, dibujante y arquitecto de origen vasco nació en 1884. En el mes de septiembre de 1929 realizó una exposición en San Sebastián, junto con el pintor Gustavo de Maeztu, el escultor José Díaz Bueno y el pintor M. Flores Kaperotxipi. Colaboró en el periódico La Voz do Guipúzcoa donde sus notas diarias tenín buena acogida pública. Formó parte del grupo GU y trabajó con el arquitecto José Manuel Aizpurua por emplo en Aizpurua por ejemplo en el Nuevo Hospital de San Sebastán (1931), Centro de Alracción y Turismo (1932), Pasteleria Saca y Escuelas de Ibarra (1930) y con el pintor Juan Cabanas Erauskin. Tenía

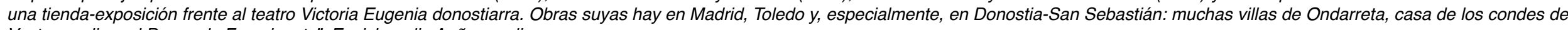
Vastameroli en el Paseo de Francia, etc". Enciclopedia Auñamendi. 


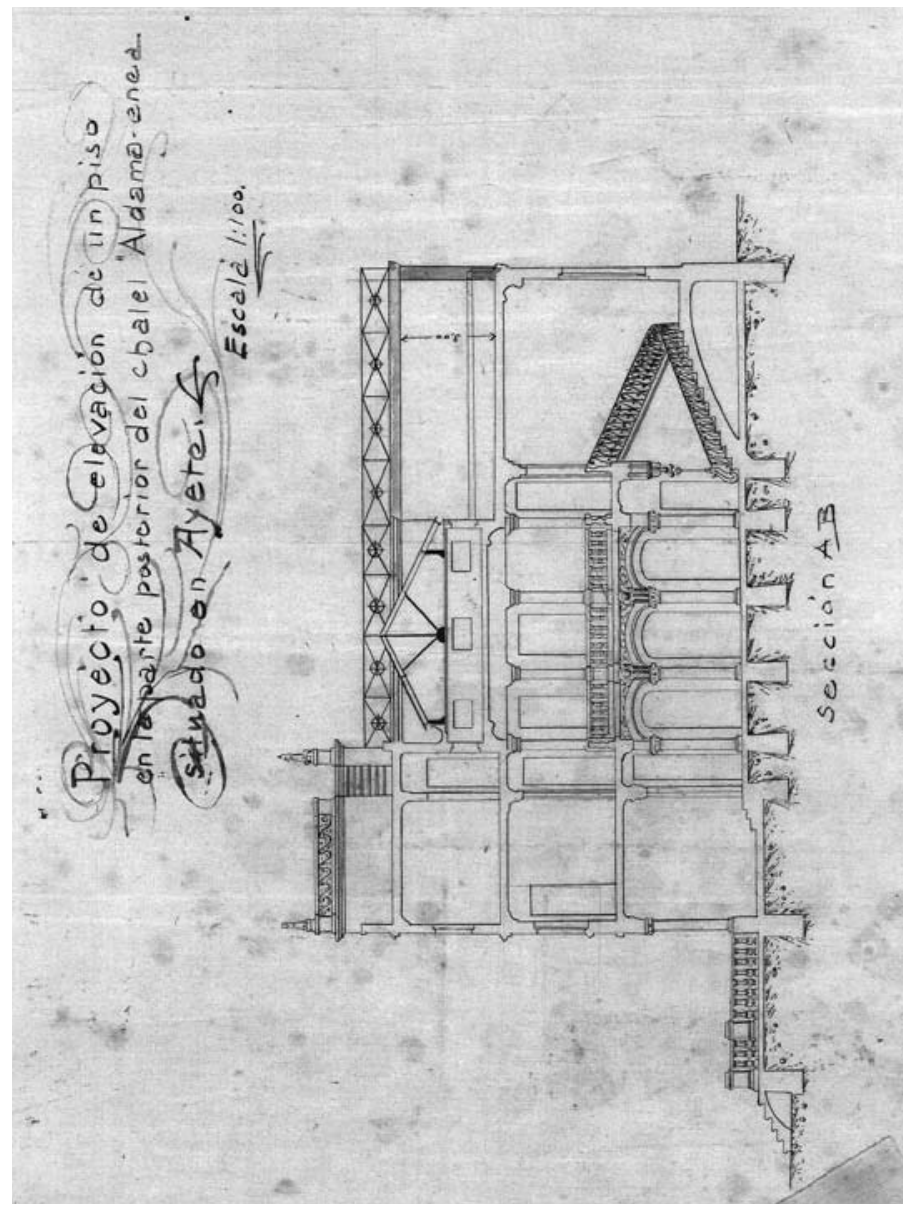

Fig. 5) Donostia-San Sebastián. Aldama-Enea. Plano del alzado. Archivo del Ayuntamiento de Donostia-San Sebastián

\subsection{Vidrieras}

La presencia de vidrieras artísticas es notable en este edificio. Todas ellas pertenecen a la firma comercial francesa Casa Maumejean con sede en París, Barcelona, Madrid y San Sebastián. Esta empresa fundada en 1860 realizó numeroso trabajos para edificios, públicos, civiles, religiosos, palacios y grandes casas burguesas. Se pueden citar las catedrales de Pamplona, Burgos, Murcia, Sevilla, Vitoria y el palacio episcopal de Astorga. Son destacados los trabajos en Madrid como los del Casino, el hotel Palace o el Banco de España y fuera de la capital los de la Diputación de Oviedo o el Ayuntamiento ${ }^{27}$, el palacio de Justicia y hotel María Cristina de San Sebastián.

El primer miembro de la dinastía Jules Pierre Maumejean, descendiente de artistas pintores de loza, se formó en las Escuelas de Bellas Artes y talleres de Burdeos y París. Abrió en 1860 un taller en Pau dedicado a la elaboración de vidrieras para iglesias y pinturas murales ${ }^{28}$. Sus hijos varones continuaron con el oficio del padre. Los talleres de diseño se encontraban en Hendaya, París y San Sebastián. La producción fue muy amplia trabajando en distintos estilos y edificios. Encontramos vidrieras clásicas, historicistas, modernas, con motivos heráldicos, cenefas, grisallas y de animales, flores o frutas ${ }^{29}$. Emplearon técnicas tradicionales como el emplomado pero también trabajaron el Cloisoné.

Dentro de Aldama-Enea las vidrieras se sitúan en el hall, las ventanas de la terrazacubierta, la puerta del antiguo recibidor, la escaleray los antiguos aseos. Nos detendremos en las dos principales y las dos pequeñas de estilo Art déco.

27. CAMPOS ORAMAS, J., “J.H. Mauméjean Hnos. La vidriería artística”, Vegueta: Anuario de la Facultad de Geografía e Historia, № 2, 1995-1996, pp. 209-218.

28. DAVID, N., "José y Enrique Mauméjean Lalanne", Gaceta del Casino de Madrid.

29. PASTOR REY DE VIÑAS, P., Vidrieras del taller Maumejean en las Colecciones de la real Fábrica de Cristales de la Granja, Taller Imagen, 2005. SAN SEBASTIÁN. DV. 
La Claraboya del hall es la principal de las vidrieras del edificio tanto por su complejidad como por sus proporciones (Fig. 6). La estructura se adapta a la segunda planta con las esquinas de la barandilla achaflanadas aumentando ligeramente la apariencia de octógono de dicha planta. La cenefa también de proporciones considerables consiste en roleos vegetales, cornucopias y cuatro escudos heráldicos.

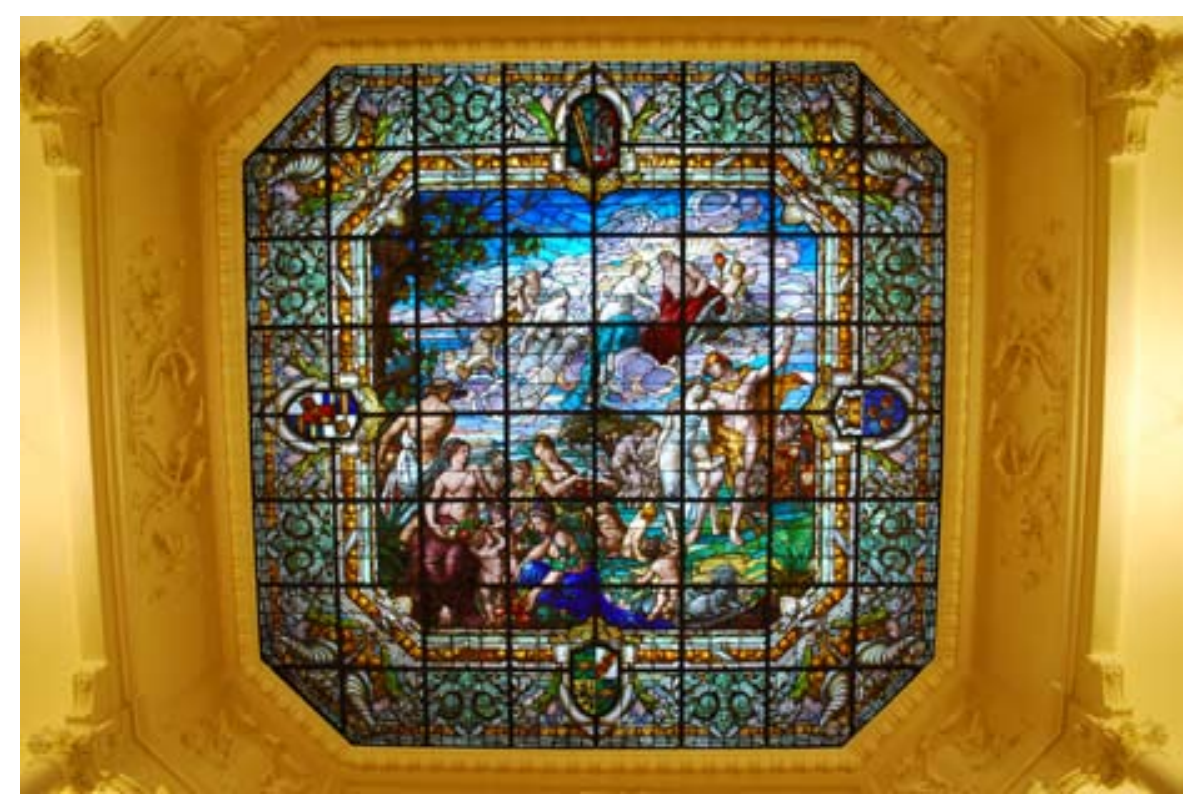

Fig. 6) Donostia-San Sebastián. Aldama-Enea. Claraboya del hall. Casa Maumejean. 1913
Nos encontramos ante una escena alegórica en la que se representa el cielo con algunos dioses del panteón griego y la tierra con sus habitantes humanos y mitológicos. Entre los dioses destacan Zeus y Hera que aparecen con las manos entrelazadas y acompañados por sus atributos: el águila y el pavo real, respectivamente. Debajo de ellos hay tres grupos de personas. A la izquierda unas mujeres con niños y dos sátiros con los frutos del campo y del ganado representado por la oveja y el cordero. En un segundo término a la derecha se representa a dos jóvenes caminando con un niño y dos sátiros y al fondo un sátiro y una mujer que amamanta a un niño en brazos, rodeados por otros cinco.

El conjunto tiene un claro sentido alegórico que hace referencia al amor matrimonial. La paz entre los cónyuges representados por Zeus y Hera, cuyas habituales desavenencias no necesitan ser recordadas, tiene como fruto el amor - la pareja de jóvenes que caminan juntos- la abundancia o la prosperidad, representada en primer término, y la fecundidad de la familia al fondo. La interpretación de la iconografía se reafirma al conocer las fuentes que se utilizaron para la composición del tema. Al menos se trata de cuatro o cinco pinturas de Rubens relacionadas con sus pinturas alegóricas y mitológicas: Encuentro de María de Médicis y Enrique IV en Lyon del Museo del Louvre, Minerva protege a Pax de Marte o Alegoría de la Paz y la Guerra del National Gallery de Londres, alguno de los modelos de Venus y Adonis ${ }^{30}$ y la cabeza del sátiro que se observa en el primero de los grupos tampoco cabe duda que sigue modelos rubenianos por la fisonomía del rostro del personaje que podemos encontrar tanto en la pintura Sátiro y joven del museo Residenzgalerie de Salzburgo como en Dos sátiros del Alte Pinakothek de Munich ${ }^{31}$.

30. Rubens, Pieter Paul, Venus and Adonis, c. 1614, The Hermitage, St. Petersburg

31. Satyr and Girl, c. 1615, Residenzgalerie, Salzburg; Two Satyrs, 1618-19, Alte Pinakothek, Munich 
Además de la calidad de esta pieza, la vidriera destaca por ser un compendio de distintos cuadros y modelos de Rubens que han sido seleccionados y adaptados a una temática coherente y absolutamente distinta a la original.

En el rellano de la escalera principal encontramos una vidriera en el gran vano del muro cuyas dimensiones son de 1,15 x 2,08 m. (Fig. 7). Precisamente de esta obra se conserva un boceto con una leyenda en la que se menciona el destino de la misma el "palacio del Escmo. Sr Maques de Aldama"B2. El tema principal, un caballero montado a caballo, recuerda a los retratos ecuestres de Velázquez, incluso el personaje tiene cierto parecido con el retrato del Conde-Duque de Olivares conservado en el Museo del Prado. Como se verá los marqueses volverían a encargar una vidriera, también para la escalera de su residencia en Madrid, nuevamente con un tema velazqueño, el retrato ecuestre del infante Baltasar Carlos.

Los motivos de la cenefa en cambio no corresponden al mismo periodo que la escena principal pues tiene elementos neoplaterescos inspirados quizás en los grutescos de guirnaldas, cintas y arreos militares. Esto no es de extrañar pues fue habitual que uniesen estilos dispares en numerosas obras ${ }^{33}$.

En cuanto a las vidrieras Art déco debieron ser encargadas a la misma casa, como consta en una de ellas, en un momento posterior y posiblemente motivado por la reforma de los aseos con la llegada del segundo propietario.

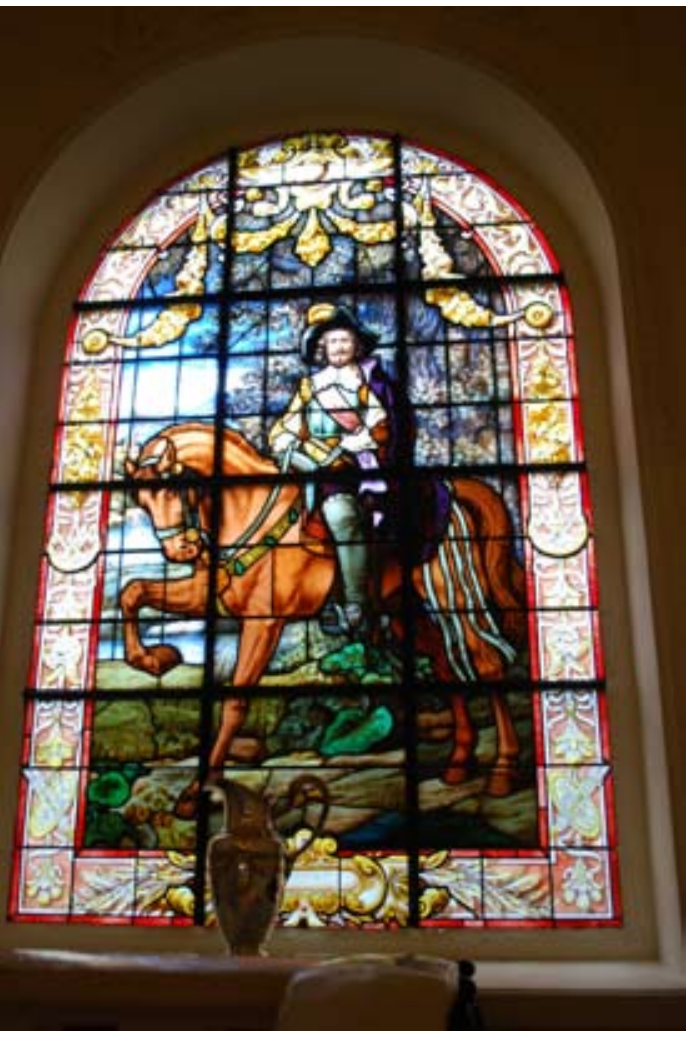

Fig. 7) Donostia-San Sebastián. Aldama-Enea. Vidriera de la escalera principal. Casa Maumejean. 1913

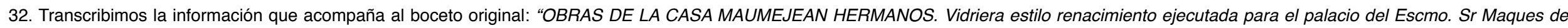
Aldama.

SAN SEBASTIAN. Y EN LA PARTE INFERIOR.- (1,15 x 2,08 m.)

MADRID: PASEO DE LA CASTELLANA 64 FABRICAS EN PARIS Y SAN SEBASTIAN".

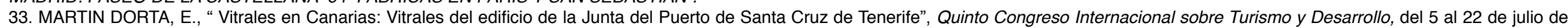

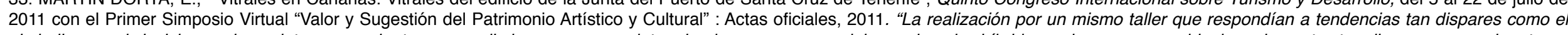

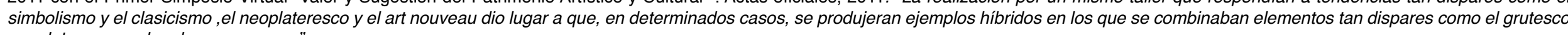
neoplateresco y el arabesco nouveau" 
La mayor, la conservada en la puerta del torreón, se encontraba en el cuarto de baño desaparecido de la segunda planta. El motivo que se representa es un loro, acompañado de flores y se puede apreciar cierta geometrización de los motivos decorativos de carácter vegetal.

El nuevo estilo se acentúa más aún en esta pequeña ventana en la que se representa de forma geométrica un gran jarrón de flores (Fig. 8). Las calidades de los vidrios son mayores así como la presencia del negro. En este caso la vidriera no conserva la firma de la casa y desconocemos si debió ser modificada al instalarla en una nueva estructura.

Este tipo de vidriera Art déco, con sus formas geométricas y restricciones de color, tuvo un amplio desarrollo en Madrid durante los años veinte y treinta impulsado por una arquitectura que integraba la vidriera como un componente fundamental.

De la misma época se conservan en Madrid este tipo de vidriera en concreto en el edificio de viviendas de la calle Marqués de Cubas, 25. Los temas muestran una iconografía relacionada con el progreso y la mecanización. Se utilizan a semejanza del presente ejemplo vidrio incoloro de texturas muy acentuadas y de gran variedad ${ }^{34}$. Se compaginan vidrios translúcidos con un color reducido al blanco, gris y negro. Tan sólo la vidriera del loro presenta algunos detalles de color amarillo en el pico y las patas.

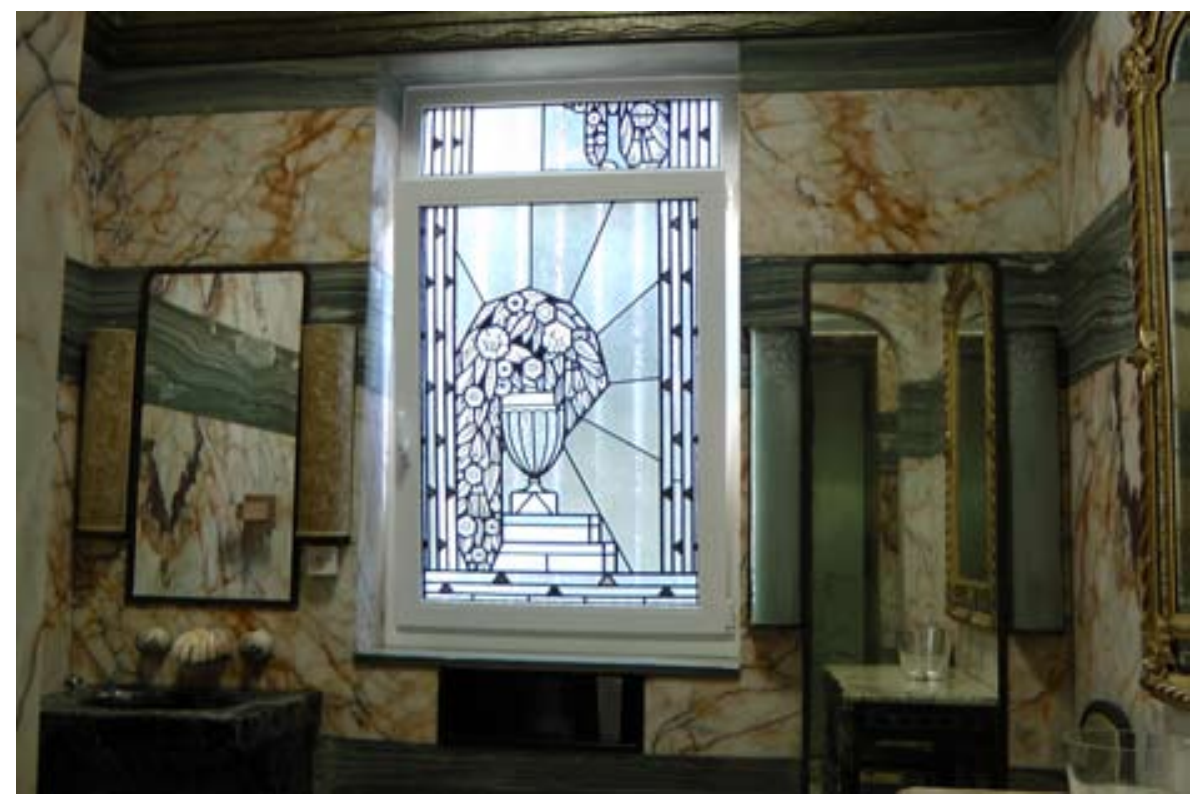

Fig. 8) Donostia-San Sebastián. Aldama-Enea. Vidriera del aseo principal. Casa Maumejean. ca.1930

\subsection{Azulejería}

En Madrid la cerámica aplicada se vinculó con los estilos autóctonos, es por esto que se asociase a comienzos del siglo veinte con corrientes regionalistas y nacionalistas. Desde antiguo destacaron importantes centros, de sobra conocidos, como eran Talavera en la zona de Castilla y Sevilla en Andalucía. El resurgir de los trabajos cerámicos y la presencia de destacados ceramistas como Zuloaga, Ruiz de Luna y Guijo o Francisco Arroyo hizo posible que estos pudiesen intervenir en obras vinculadas al modernismo y 
eclecticismo $^{35}$. La presencia de azulejos en la producción arquitectónica de José María Mendoza Ussía no se redujo a este edificio. Hay que destacar el edificio Papelera Española en la calle Mejía Lequerica ${ }^{\circ} 8$-actual Edificio Gil y Carvajal- realizado entre 1913 y 1915 donde incluyó un friso bajo la cornisa del edificio del taller Ruiz de Luna. Dentro del edificio tres zócalos decoran la sala andaluza y los dos pisos del patio central. Nos vamos a detener en la azulejería trianera y talaverana ${ }^{36}$.

\subsubsection{Zócalo de la sala andaluza}

Es posible que la cerámica que decora este espacio procediese de la conocida fábrica de José Mensaque y Vera ${ }^{37}$. Son azulejos de relieve o arista producidos en torno a 1900 y 1910 (Fig. 9) ${ }^{38}$. Precisamente aquel fue un momento de apogeo del azulejo y la cerámica trianera. La casa, cuya producción se caracterizó por la gran calidad técnica y de diseño, obtuvo numerosos premios nacionales e internacionales ${ }^{39}$.

En la sala que nos ocupa nos encontramos principalmente con motivos que se repiten como los tradicionales geométricos pero consistentes en flores $y$ argollas que se entrelazan junto con alguna gran loseta heráldica con el águila bicéfala, el "PLVS VLTRA" y el escudo de los Enríquez tomado de la Casa de Pilatos en Sevilla con los dos castillos y el león rampante.

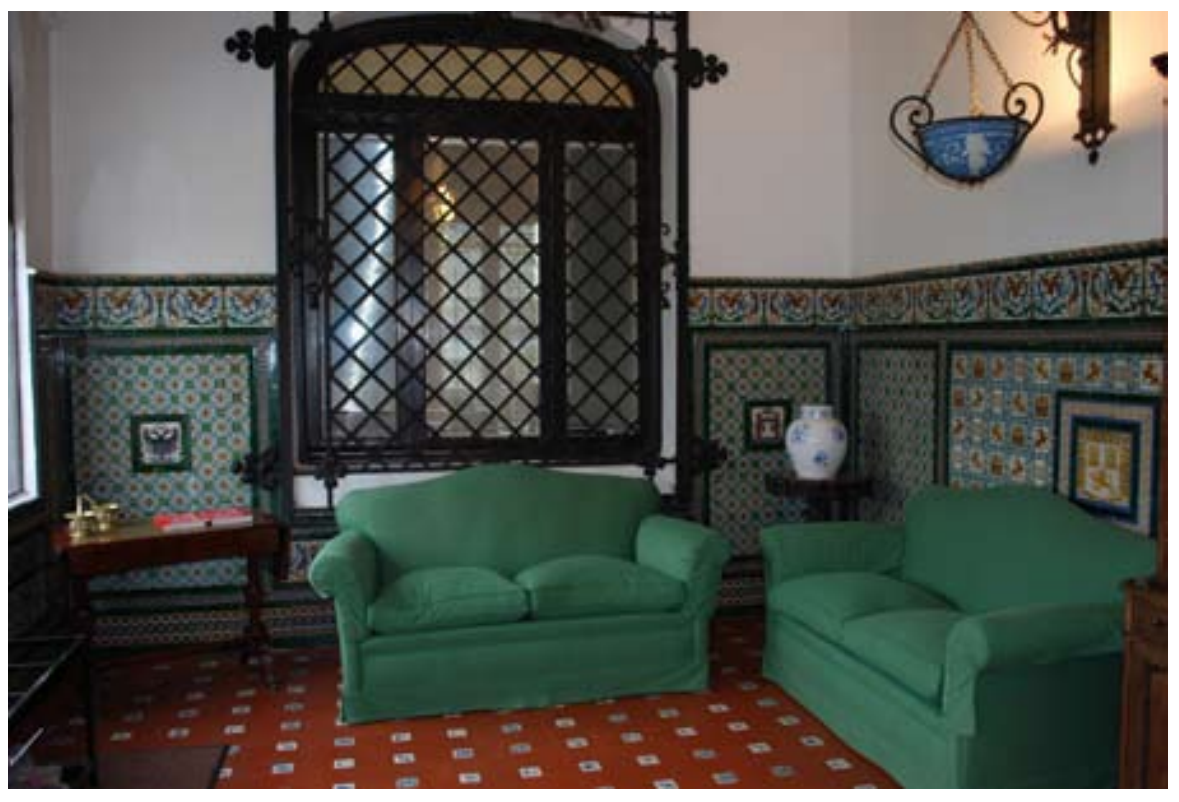

Fig. 9) Donostia-San Sebastián. Aldama-Enea. Zócalo de la sala andaluza. José Mensaque y Vera

35. ROCHA ARANDA, O. da, El modernismo en la arquitectura madrileña. Génesis y desarrollo de una opción ecléctica, CSIC, Madrid, 2009 , p. 199 y 201.

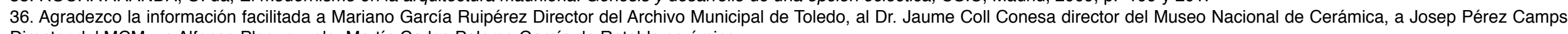
Director del MCM y a Alfonso Pleguezuelo, Martín Carlos Palomo García de Retablo cerámico.

37. Agradecemos el asesoramiento que Martín Carlos Palomo García, colaborador de la web retablo Cerámico, nos ha dispensado tan amablemente.

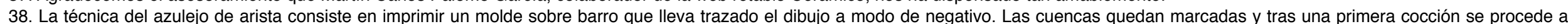

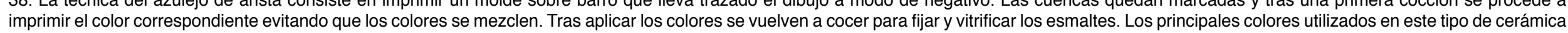

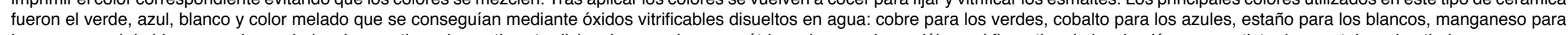
los negros y el de hierro para los melados. Los motivos decorativos tradicionales eran los geométricos de esencia mudéjar y el figurativo de inspiración renacentista de vegetales y bestiarios.

39. "Exposición Universal de París de 1889, en la de las Industrias Artísticas de Barcelona de 1892, en la Exposición Universal de Chicago de 1893, en la de Artes e Industrias de Barcelona de 1896, quedando primero de su categoría en la Exposición Nacional de Valencia de 1910" 
Estos motivos originales se encuentran en el cenador de los jardines de los Alcázares Reales de la misma ciudad. Además de exaltar los valores nacionales propios de la época no es casualidad que esa simbología esté relacionada con el hecho de la pertenencia del marqués a la orden de Isabel la Católica en cuya medalla están presentes las columnas con el mencionado lema y el orbe azul ${ }^{40}$.

En cuanto a la procedencia de estos azulejos al consultar el catálogo de piezas de la Fábrica Mensaque Rodríguez encontramos algunos de los motivos de las cenefas como las que representan algunas figuras humanas y aves metamorfoseadas con roleos vegetales o los motivos heráldicos. Nos reafirmamos en el origen al encontrar las mismas losetas en uno de los bancos trianeros de los jardines de la casa de Joaquín Sorolla, quien prestó gran atención al diseño del que sería lugar y modelo de la pintura de su última etapa. El jardín de la Casa Sorolla logró sintetizar el estilo neoárabe o neosevillano de la época muy en boga a finales del siglo XIX y principios del siglo XX, momento en el que surge un movimiento de recuperación historicista de los grandes estilos de jardinería de épocas pasadas asimilándolos al carácter nacionalista de aquel momento ${ }^{41}$. No es casualidad que también el pavimento sea prácticamente idéntico al de los jardines mencionados a base de ladrillo rojo fino prensado que se combina con alhambrillas u olambrillas policromadas de azul con distintos motivos ${ }^{42}$. Al tratar el siguiente zócalo podremos estrechar más todavía la relación con la Casa Sorolla.

Tanto los estilos neoárabe como el neosevillano se asociaron pronto a tipologías relacionadas con la diversión, el ocio como cafés, villas de recreo o kioskos y gozaron de gran aceptación en balnearios, teatros, casinos y plazas de toros. Ya sea el afán por evocar el mundo oriental o en versión nacionalista tomando como referencia el mencionado cenador de Carlos V la finalidad de caracterizar este espacio de este modo no debió ser otra que la de crear un espacio con un gran componente lúdico y de evasión. Ejemplos de moda oriental, uniéndose al cosmopolitismo de las exposiciones universales y del joie de vivre, los encontramos en Biarritz, Hendaya, en el balneario de Cestona o el chalet Azelaincho que existió en el barrio de $\mathrm{Gros}^{43}$.

\subsubsection{Zócalo de azulejos de Ruiz de Luna}

De entre los tres zócalos que se conservan en el edificio destaca este que ocupa la primera planta. Además de la firma y fecha que se conserva en los azulejos, el único dato relativo a su realización lo encontramos en el catálogo publicado sobre el artista en el centenario de la fábrica, donde se recoge con fecha de 1913: "Zócalo de azulejos para el comedor del Hotel del marqués de Aldama en San Sebastián (arquitecto J. Mª . Mendoza y Ussía)".

Juan Ruiz de Luna fue un destacado ceramista toledano que en los primeros años del siglo $X X$ se percató del rico patrimonio existente y se volcó en su estudio y producción con la creación de la fábrica "Ruiz de Luna e Guijo y Cía". Además de querer devolver el esplendor pasado a este arte, rescató técnicas antiguas pero reinterpretándolas y aplicando mejoras en dibujos y colores que antes eran imposibles de lograr.

40. Poseía la Gran Cruz de Isabel la Católica y Gentilhombre de Cámara con ejercicio y servidumbre.

41. LUQUE MENSAQUE, B. "La cerámica trianera en el jardín de Sorolla", Fundación Casa Museo de Sorolla, Pieza del mes de Octubre 2012.

42. BERLINCHES ACÍN, A. (Dir. ), Arquitectura de Madrid, Ensanches, Madrid, Fundación COAM, 2003, p. 145.

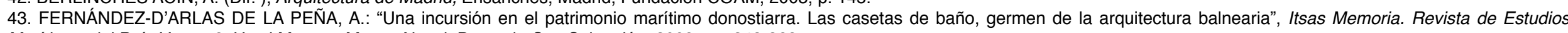
Marítimos del País Vasco, 6, Untzi Museoa-Museo Naval, Donostia-San Sebastián, 2009, pp. 343-368. 
En 1907 Enrique Guijo pintor, decorador, ceramista y restaurador viajó a Talavera de la Reina donde conoció a Juan Ruiz de Luna y ambos fundaron la Fábrica de Cerámica Artística Nuestra Señora del Prado. Éste artista cordobés se formó en Sevilla en tres talleres, destacando el de la familia Mensaque y el de Manuel Rodrígue ${ }^{44}$. Esto nos lleva a pensar que no debe ser casualidad la procedencia del zócalo trianero proveniente del primer taller mencionado. Durante el periodo de trabajo de los dos socios, Ruiz de Luna se valió de distintos contactos para difundir su obra. Podemos citar al marqués de Comillas, a Archer M. Huntington -fundador de la Hispanic Society de Nueva York- Mariano Benlliure, Sorolla y numerosos arquitectos con los que se ejecutaron algunos de los proyectos: L. Bellido en Madrid, con el que se trabajó para la Casa Cisneros; L. Rubalcaba, a través del cual la cerámica de Ruiz encontró un amplio mercado en Bilbao; E. Daverio en Granada; Arnós Salvador en Irún y J. Mª Mendoza y Ussía en Madrid ${ }^{45}$.

En el presente momento podemos añadir que en ese afán de expansión, y aprovechando el contacto de J. $\mathrm{M}^{\mathrm{a}}$ Mendoza y Ussía, se entiende la presencia de este zócalo en Aldama-Enea y en otras obras realizadas en torno a 1913. Podemos citar los paneles de la fachada de "La Papelera Española" y los cuadros heráldicos en la escalera del palacio del marqués de Cubas en Madrid como consta en la documentación conservada ${ }^{46}$.

De la misma fecha un "zócalo de azulejos de un saloncito y de la galería del patio del Hotel de Joaquín Sorolla en Madrid ${ }^{\text {,47 }}$. Nuevamente se explica la presencia de las cerámicas de los talleres donde trabajó Enrique Guijo. Todos ellos debieron estar relacionados de algún modo del que no tenemos constancia. Precisamente el mismo Sorolla frecuentó el palacio Lamuza, residencia de veraneo de Estanislao de Urquijo y Ussía, tercer marqués de Urquijo, director del Banco Urquijo, cuyo edificio construyó su primo José María Mendoza y Ussía ${ }^{48}$.

El zócalo en cuestión fusiona tres estilos distintos. Encontramos motivos propios de las series barrocas o de roleos de la fábrica como la serie renacentista o de guerreros y la de batallas ${ }^{49}$. El zócalo consta de un friso con motivos que se repiten que rodea todo el conjunto de cada uno de los lienzos de pared entre las numerosas puertas que dan al hall y que divide en dos partes cada panel. La tonalidad predominante es el azul cobalto bajo cubierta incolora, inspirándose en los trabajos talaveranos.

En el panel inferior encontramos roleos de tallos y hojas que se mezclan con figuras zoomorfas, cartelas de cueros retorcidos con decorados con motivos de batallas y soldados. Es en estas escenas donde se incluye el color, principalmente el azul, naranja y manganeso.

La fuente de inspiración de estas escenas se encuentra en los zócalos de azulejería de la Sala Capitular baja del Ayuntamiento de Toledo, realizado por Ignacio Mansilla del Pino en 1696. Las escenas se denominaron en el encargo como "países de batallas", paisajes con batallas, y es posible que

44. Catálogo "El arte redivivo. Exposición del I Centenario de la Fábrica de Cerámica Ruiz de Luna Nuestra Señora del Prado". Talavera 2008, p. 28.

45. Ibíd., p. 21

46. Ibíd., p. 89

47. Ibíd., p. 21

48. DÍAZ HERNÁNDEZ, O., Los marqueses de Urquijo: el apogeo de una saga poderosa y los inicios del Banco Urquijo, 1870-1931, Universidad de Navarra, Ediciones Universidad de Navarra. EUNSA,

1998. http://www.euskalnet.net/laviana/gen_bascas/urquijo.htm

49. Catálogo "El arte redivivo..., p. 34-36. 
evocasen los tercios de Flandes ${ }^{50}$. La única escena que no está representada en la citada sala de Toledo es la que representa a tres personajes de la antigüedad que podemos relacionar con Constantino, tocado con la corona de laurel, en la batalla del puente Milvio al aparecer el lábaro con el monograma de Cristo.

Ruiz de Luna y su discípulo Francisco Arroyo, impresionados por la calidad del zócalo mencionado, tomaron estos modelos que posteriormente representaron con toda fidelidad en distintos elementos como platos, jarrones y el presente zócalo. En el catálogo de la exposición celebrada con ocasión del primer centenario de la creación de la fábrica se indica que la producción relacionada con este tema hay que situarla en torno a 1920 salvo algún ejemplo como el de un gran plato de los primeros años del taller. Ahora podemos apuntar como ejemplo de la continuidad de estos motivos en el zócalo del marqués de Aldama en 1913.

El segundo nivel del zócalo está decorado también con seres antropomorfos entre acantos con los que se metamorfosean. Dos de estos seres sostienen entre sus manos un tondo con la cabeza de un guerrero tocado con un casco de carácter totalmente renacentista. Otros tondos aparecen simplemente enmarcados en las cartelas y con roleos vegetales. Estos motivos fueron traídos al taller por Enrique Guijo al estar en relación con las producciones de la azulejería renacentista sevillana.

\subsection{Pasado y presente del edificio}

Por todo lo visto hasta ahora podemos observar el cuidado del arquitecto al diseñar un edificio moderno para su momento con una decoración historicista que se hace presente hasta el último detalle. Por los muebles que han sobrevivido a los cambios que ha sufrido el edificio y fotografías antiguas vemos que ese estilo también se extendió también a estos elementos. Podemos ponerlos en relación con otros semejantes que decoraron la residencia de los marqueses de Aldama en la capital, si bien la referencia que tenemos es de la que ocuparon en 1924. Contamos con una pormenorizada descripción en un artículo dedicado a la casa en la revista Blanco y Negro de aquel año.

Parece ser que los marqueses cambiaron de vivienda al adquirir un inmueble en construcción y la decoración se realizó con la compra de obras de arte y mobiliario español y extranjero. Muchos de los muebles se caracterizaron por su casticismo: sillones fraileros, mesas de complicadas tallas y hierros, facistoles, fragmentos de una sillería de coro y "damascos de color prelado", expresión frecuentemente repetida en la época que fue tomada de Emilia Pardo Bazán. Una escalera desde el hall subía a la primera planta en cuyo ventanal, al igual que en Aldama-Enea, había una vidriera que reproducía el retrato ecuestre del príncipe Baltasar Carlos realizado por Velázquez para el Salón de Reinos del palacio del Buen Retiro. Todo el conjunto, como se indica en el reportaje, pretendía evocar "el recuerdo de las estancias palatinas de Carlos V y Felipe II".

La alfombra de la escalera fue encargada a la Real Fábrica de Tapices tomando como inspiración los tapices del XV y en concreto copiando los de los salones del palacio de Viana. Otras zonas de la residencia también se seguían decorando con arcones cubiertos de terciopelos carmesís, reproducciones célebres retratos antiguos y originales de paisajistas holandeses o del Greco, puertas procedentes de iglesias, cornucopias y biombos, relojes y candelabros. En el salón de baile, tapizado de damasco 
azul oscuro, destacaba un tapiz flamenco y un mueble denominado Rouleque se creía había sido realizado para el príncipe de Condé en época de Luis XIV.

A través de las imágenes publicadas en el reportaje podemos observar todo tipo de elementos arquitectónicos y cubiertas neoplaterescos que recuerdan poderosamente a lo que se ha conservado en su antigua residenciadeverano ${ }^{51}$.

La admiración y las alabanzas al buen gusto de la marquesa es un claro ejemplo de lo que tanto criticaban los teóricos más importantes de la arquitectura española de esos años. Leopoldo López Balbás se lamentaba de que los aristócratas y burgueses llenases sus palacios con objetos de épocas diversas, muchas procedentes de monasterios e iglesias confiriendo "un aire a mitad de camino entre sacristía y tienda de chamarilero" por el mero afán de aparentar ${ }^{52}$.

En el caso de Aldama-Enea desde el año 1963, pese a que el edificio ha ido modificándose en algunos aspectos para su funcionalidad, ha respetado el espacio principal que es el hall y las estancias de la primera planta. El interior perdió gran parte de los elementos que la hacía parecer un espacio doméstico. Aunque no se cambiaron inmediatamente, se sustituyeron los papeles de seda rojos que cubrían las paredes del hall por encima de los zócalos de cerámica y el gran cortinón que cubría parte del hueco de la escalera principal. A pesar de la gran transformación de habitaciones en aulas y despacho muchos elementos del mobiliario original permanecieron en el edificio: la mesa central y las sillas, que pertenecían al comedor aunque con distinta tapicería, las lámparas y apliques, dos percheros artísticos de madera que fueron transformados en lámparas, un tresillo, dos butacas y dos bancos, uno de ellos de madera y cuero con motivos decorativos semejantes al del resto de hall con cabezas de soldados. Del despacho o gabinete se adquirió un mueble que contenía la librería cerrada, realizada en madera de encina moldurada. En la película mencionada se observa el carácter masculino de la estancia, lugar de trabajo. Se eliminó el papel y madera que recubrían las paredes siendo en la actualidad una estancia anodina del mismo modo que la antigua capilla.

Del comedor se adquirieron dos alfombras, dos lámparas, la mesa, unos sillones y varios apliques, de los que sólo se conservan estos últimos. De los pasillos y escaleras se quitaron las alfombras. La hermosa alfombra del hall, muy probablemente de la Real Fábrica de Tapices, con el tiempo fue sustituía por otra de menor calidad.

También fue el momento en el que se desmontó un baño para hacer una salita en la segunda planta. De este cuarto de baño se conservó la vidriera decó que se insertó en la puerta de acceso de la escalera del torreón.

En muchas de las estancias se bajaron los techos y se quitó el papel original ${ }^{53}$. Posteriormente se realizaron obras de reparación y mantenimiento en 1994, momento en el cual se debieron suprimir los pináculos del torreón y se cambiaron las ventanas. En el año 2000 se llevaron a cabo labores de restauración en la vidriera principal y en el 2004 se modificó la estructura del lucernario ${ }^{54}$. En fecha reciente los azulejos de Triana fueron restaurados por la empresa Acanto al igual que las rejas del antiguo acceso.

51. Blanco y Negro 27/01/1924, p. 36-38. "Residencias aristocráticas, La casa palacio de los marqueses de Aldama".

52. BLASCO ESQUIVAS, B. et alii, La casa. Evolución del espacio doméstico en España, vol. 2 Edad contemporánea, Ediciones El Viso, Madrid, 2006, p. 95.

53. Archivo ISSA. Reformas de 1974

54. Metalúrgicas Mendía y Murua S.L Estructura del lucernario. Se superpuso una estructura con forma de octógono compuesto por franjas visibles de hormigón armado y vigas de acero. 2004. 


\section{Otros espacios y dependencias de la finca}

La dimensiones de los "paseos y jardines" eran notables, $30.128 \mathrm{~m} 2$ (Fig. 10). Del mismo modo que en el caso del palacio del marqués de Cubas, José María Mendoza proyectó los jardines haciendo que el edificio estuviese rodeado por todos sus lados.

Además de seguir el modelo de los jardines que se diseñaban en torno a las hoteles y palacios de la Castellana o del barrio de Salamanca, en San Sebastián había ya una gran tradición de jardinería con ejemplos tan notables como los realizados por Pierre Ducasse para el Duque de Bailén, el de Cristina enea, Toki eder en Ategorrieta, para el marqués de Valdespina en Astigarraga o el palacio real de Miramar. Todos estos palacios se construyeron en el centro de sus respectivos parques ${ }^{55}$. Desconocemos prácticamente todo acerca del jardín. Conociendo el terreno, aunque actualmente urbanizado, podemos decir que el edificio está situado en el lugar más idóneo para contemplar las vistas y para que el edificio tuviese gran visibilidad desde la ciudad. A través del plano presentado en el Ayuntamiento en 1912 podemos observar que parte del mismo, lo que se extendía detrás del edificio principal, muestra una división en parcelas a modo de jardín francés incluyendo un espacio con una fuente circular y un zócalo de mármol que lo rodeaba. La fuente fue trasladada tras la venta de los terrenos y comprada por el Ayuntamiento que la destinó para embellecer el final del Paseo de Francia espacio en el que se encuentran también las fuentes Wallace. La situación de la misma se encuentra frente a la Estación del Norte, creando una pequeña plaza a un lado.

En este vasto terreno se dispuso un edificio para las cuadras y cocheras y una casita para el guarda. Esta última sería reformada por el arquitecto Eduardo Lagarde ${ }^{56}$.

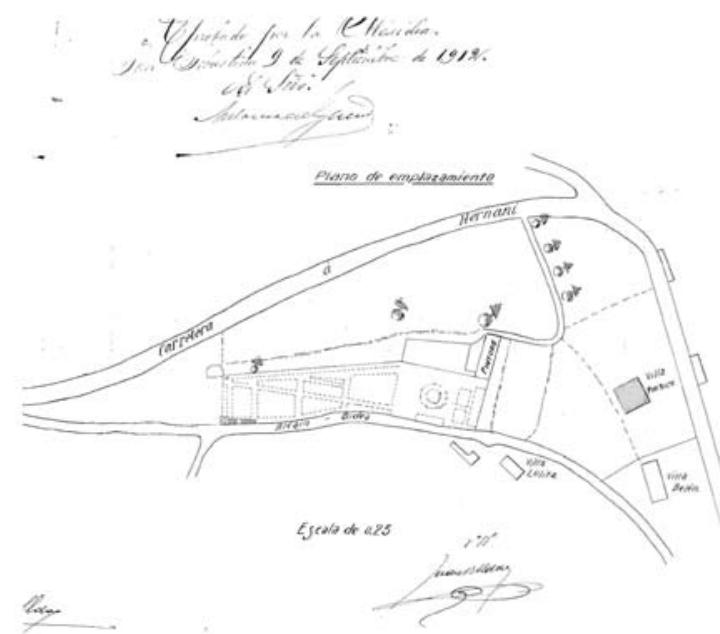

Fig. 10) Donostia-San Sebastián. Aldama-Enea. Plano de la finca. Archivo del Ayuntamiento de Donostia-San Sebastián

Parece que el resto del espacio de la finca debió de estar constituido por un arbolado quizás dispuesto paisajísticamente con algún elemento como pedestales con jarrones de piedra, al menos estos elementos estaban presentes en la citada película de Elorrieta, El diablo en vacaciones. También sabemos que en los años 40 y 50 se conservaban el jardín francés con setos recortados y existía una pista de tenis. Desconocemos si la pista es anterior a 1925 pero no es descabellado que lo fuese ya que constituye otro signo de cosmopolitismo y modernidad. El deporte o sport-término generalizado entonces- se abría camino entre la aristocracia y la alta burguesía española a través del tenis, las regatas o las carreras de coches, precisamente parte

55. MUÑOZ ECHABEGUREN, F., San Sebastián. Palacios, parques y jardines, EREIN, Donostia, 2012, p.11.

56. A.A.S.S., Sección de Archivo, H-02427-15. Proyecto de reforma y ampliación para la portería de la Villa Eva-Enea. 
de la oferta que se podía encontrar en una ciudad como San Sebastián ${ }^{57}$.

Uno de los elementos más notables de la finca fueron las caballerizas y cochera, desde hace unos años denominada Etxe-Zuri. Hasta la actualidad el edificio ha sido considerado de autor desconocido pero gracias a los proyectos y planos conservados en el Archivo del Ayuntamiento de San Sebastián podemos afirmar que al igual que el edificio principal el diseño de este es del mismo arquitecto, Mendoza y Ussía (Fig. 6).

En la escritura de edificación se recogen las distintas estancias que se proyectaron y que se observa en los planos: "Cuadras, cochera y garajes. La construcción es igual a la ya detallada en el hotel, con las variantes propias del uso a que se destinan, los suelos son de cemento y piedra; la cuadra tiene cuatro plazas para caballos y dos jaulas de madera y hierro; la cochera, así como los garajes tienen un friso de azulejo valenciano y el resto de pintura al temple; en el piso alto de estos edificios existen las habitaciones para la dependencia, compuestas de salones y alcobas con suelos entarimados y paramentos blanqueados; este edificio ocupa una superficie de trescientos ochenta y un metros y ocho decímetros cuadrados y su valor estima en sesenta mil pesetas" 58 .

El edificio, de planta rectangular con una y dos plantas de altura, presenta interés por la semejanza con la decoración de la casa principal ${ }^{59}$. Comparte con esta última la característica galería de arquillos con columnillas de la parte superior.
Hoy en día no ha conservado las molduras en el entablamento, los entablamentos y remates decorativos de los vanos inferiores y los pináculos semejantes a los de la casa principal que se observan en los planos ${ }^{60}$.

Con la segregación de la finca en 1960 el Ayuntamiento adquirió el edificio. En 1972 se decidió reformarlo para que sirviese de dependencia del Ministerio de Jornada, debido a que el ministro de Asuntos Exteriores veraneaba en "La Cumbre", edificio a escasos metros de éste.

El edificio se vio modificado creándose un vestíbulo central cubierto por una cristalera y distintas dependencias a las que se accedía a través del mismo. Entre 1975 y 1976 el Ayuntamiento cedió la mitad del edificio a la Diputación y en 1983 fue la sede de las Juntas Generales de Gipuzkoa. En el edificio se dispusieron las dependencias administrativas y los despachos de los grupos parlamentarios, las salas de reuniones las salas de reunión de la Mesa y de las comisiones y el despacho del presidente de las Juntas Generales.

Las limitaciones del edificio para las sesiones plenarias que tenían lugar en el Palacio de la Diputación, en el palacio de Miramar y en una sala de congresos en el parque tecnológico de Miramón ocasionaron que en 2007 las Juntas Generales se trasladasen a otro lugar ${ }^{61}$. En la actualidad es la sede de Fomento de San Sebastián S.A, una sociedad pública municipal dedicada a la promoción y al desarrollo económico y social de la ciudad. El traslado se realizó en el 2014 y el edificio nuevamente ha sufrido una gran modificación en su interior.

57. ROBIN, C.N., "El deporte", Los felices años veinte: España, crisis y modernidad, Marcial Pons, Ediciones de Historia S.A., Madrid, 2006.

58. A.A.S.S., Registro de la propiedad.

59. Plan especial de protección del Patrimonio Urbanístico Catalogado. Documento V: Ordenanzas particulares. Julio 2008. Ficha del edificio protegido. Villa Urbana-Sede Juntas Generales San Roque 120. El plano incluido es erróneo y corresponde al edificio de la portería.

60. A.A.S.S., Sección de Archivo, H-02427-15. Proyecto de reforma y ampliación para la portería de la Villa Eva-Enea.

61. Juntas Generales de Gipuzkoa. Etxe Zuri, antigua sede provisional (1983-2007). http://w390w.gipuzkoa.net/WAS/CORP/DJGPortalWEB/sede.jsp. (Consultado el 14-6-2014) 


\section{Conclusión}

El presente artículo da a conocer la existencia de una obra del arquitecto madrileño Mendoza Ussía en San Sebastián, quien realizó notables edificios en la Gran Vía de Madrid, algunos de los cuales están ligados a lazos familiares con los Urquijo y Ussía. Aldama-Enea, residencia de veraneo del marqués de Aldama, es un claro ejemplo de la arquitectura neorenacentista con carácter nacional, o neoplateresco, que siguió de cerca los ejemplos de José Urioste, cuyo pabellón de España en la exposición de París de 1900 marcó el inicio de la arquitectura nacionalista o regionalista en todo país. Además también se caracterizó por poseer todos los elementos de modernidad que podía tener una vivienda burguesa de sus característica: estancias con una funcionalidad claramente definida, distribuidas también por plantas siguiendo también criterios de representación, intimidad, higienismo, además de luz, agua, aseos, teléfono, etc. Pese a que el edificio ha ido modificándose en algunos aspectos para labores docentes ha respetado el espacio principal que es el hall y las estancias de la primera planta y alguna de la segunda. El interior perdió gran parte de los elementos que la hacía parecer un espacio doméstico, pero, aún así, se conservan bastantes muebles originales que dan coherencia a todo el espacio.

También son de destacar las vidrieras de la casa Maumejean y tres zócalos de azulejos, ejemplo del renacer de esas artes en aquel momento histórico marcado por el eclecticismo en las artes. En la actualidad el estado de conservación del edificio es bueno aunque sería conveniente una pequeña restauración en el zócalo de Ruiz de Luna. Aldama-Enea o Villa Eva es un edificio que ha pasado con toda discreción y es desconocido para gran parte de la población donostiarra. Con el traslado de ISSA al campus de la Universidad de Navarra en Pamplona el futuro que le espera es incierto y es posible que el carácter doméstico para el que fue proyectado, y quizás muebles y otros elementos desaparezcan en breve. 